\title{
Crustacean Motor Pattern Generator Networks
}

\author{
Scott L. Hooper Ralph A. DiCaprio \\ Neuroscience Program, Department of Biological Sciences, Irvine Hall, Ohio University, Athens, Ohio, USA
}

\section{Key Words}

Stomatogastric system • Cardiac ganglion · Swimmeret • Gill ventilation $\cdot$ Central pattern generation $\cdot$ Rhythmic neural network · Proprioceptive feedback - Endogenous oscillation · Plateau potential · Graded synaptic transmission

\begin{abstract}
Crustacean motor pattern-generating networks have played central roles in understanding the cellular and network bases of rhythmic motor patterns for over half a century. We review here the four best investigated of these systems: the stomatogastric, ventilatory, cardiac, and swimmeret systems. Generally applicable observations arising from this work include (1) neurons with active, endogenous cell properties (endogenous bursting, postinhibitory rebound, plateau potentials), (2) nonhierarchical (distributed) network synaptic connectivity patterns characterized by high levels of inter-neuronal connections, (3) nonspiking neurons and graded transmitter release, (4) multiple modulatory inputs, (5) networks that produce multiple patterns and have flexible boundaries, and (6) peripheral properties (proprioceptive feedback loops, low-frequency muscle filtering) playing an important role in motor pattern generation or expression.
\end{abstract}

Copyright $\odot 2004$ S. Karger AG, Basel

\section{Introduction}

Understanding the genesis of rhythmic motor patterns such as walking and swimming has long been a fundamental goal of neuroscience. This interest was heightened by later discoveries that multiple simultaneous rhythms are present in brain activity, and that these rhythms change as a function of arousal and attention [1-9]. Invertebrate preparations have always played a prominent role in these studies because these preparations are often easily maintained in vitro and often have anatomically distributed nervous systems (as opposed to the highly centralized systems found in vertebrates), large neurons that are easily recorded from and repeatedly identifiable in different animals of the same species, and fixed neuron populations and synaptic connections. Indeed, the crayfish and locust were the first preparations in which it was unambiguously demonstrated that central pattern generators (CPGs) neural networks capable of spontaneously producing rhythmic, patterned neural outputs in the absence of sensory feedback or patterned central input - exist $[10,11]$. Subsequent work in a large variety of systems showed that in all cases, CPGs generate the fundamental rhythmicity and phasing of rhythmic motor patterns [12], resolving a 50 -year controversy whether such patterns were generated by spontaneous central rhythmicity or via a reflex chain in which the sensory feedback generated by each individual movement in the pattern triggered the pattern's next movement.

\section{KARGER \\ Fax +4161306 1234 \\ E-Mail karger@karger.ch \\ www.karger.com

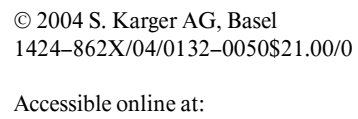

S.L. Hooper

Neuroscience Program, Department of Biological Sciences

Irvine Hall, Ohio University

Athens, OH 45701 (USA)

Tel. +1 740593 0679, Fax +1 740593 0687, E-Mail hooper@ohio.edu 
However, as often occurs when dichotomous choices are forced on data, in reality, the relative importance of spontaneous central rhythmicity and movement-induced sensory feedback varies tremendously from motor pattern to motor pattern. In particular, motor patterns such as terrestrial locomotion - in which cycle-by-cycle variation in response to a variable substrate is critical for behavioral competence, and failure to maintain proper phasing of motor pattern movements in even one cycle could be catastrophic - often so depend on sensory feedback that it is very difficult to induce isolated nervous systems to produce any rhythmic output at all. There is consequently a distinct bias in experimental work on the cellular level toward motor patterns that are less dependent on sensory input (e.g. swimming, flying, respiration, heartbeat, gut movements), although even in these cases sensory feedback often dramatically increases CPG cycle frequency and robustness of neuron firing. Evidence of this bias is present in this article by the absence of a section on crustacean walking, for which, although a great deal is known about locomotor reflexes [13-16], the CPG network remains unidentified.

Given that the primary goal of invertebrate work is to gain insight into higher, and particularly human, nervous system function, whether work on a biased subset of invertebrate CPGs can provide generally applicable principles is a valid question. Two observations suggest that this is likely true. The first is evolutionary. Vertebrates (Deuterostomia), worms and mollusks (Lophotrochozoa), and arthropods and nematodes (Ecdysozoa) all have nervous systems that support locomotory, food searching, eating, escape, and reproductive movements, and jellyfish (Radiata) have nervous systems that produce rhythmic locomotory movements. Deuterostomia, Lophotrochozoa, and Ecdysozoa separated at least 500 million years ago. Bilateria (of which Deuterostomia, Lophotrochozoa, and Ecdysozoa are branches) and Radiata separated an unknown but presumably great period earlier. These observations suggest that nervous systems capable of producing rhythmic movements arose very early in animal evolution (presumably present in the last common ancestor of Radiata and Bilateria). Despite their great subsequent divergence, it might be expected that, given evolution's generally conservative nature, remnants of this common ancestry are still present in both invertebrates and vertebrates. Second, and perhaps more convincing, history shows that this approach works. The list of neural and network properties first described in invertebrates and now known to be also present in vertebrates includes the ionic basis of the action potential, many of the known membrane conductances, CPGs, endogenously bursting neurons, plateau properties, nonspiking neurons, nonspiking (graded) transmission, neural network modulation, multifunctional neural networks, and neural networks with changing neuronal complements (e.g. neurons switching between different networks and network fusion).

Crustacean CPG networks have played key roles in many of these discoveries. We review here four crustacean CPGs that are completely or partly known on the cellular level: the extremely well-described stomatogastric system and the ventilatory, heartbeat, and swimmeret CPGs. Particularly important advances from this work include the importance of endogenous, active membrane properties in network neurons; the distributed, nonhierarchical nature of many of the network synaptic connectivity diagrams; the presence of multiple neuromodulatory inputs that alter network output; network flexibility; and the frequent presence of nonspiking neurons and graded synaptic transmission.

\section{The Stomatogastric System}

\section{Overview}

The stomatogastric neuromuscular system generates the rhythmic movements of the four regions of the crustacean stomach: the esophagus, cardiac sac, gastric mill, and pylorus (fig. 1a, b) [17]. The esophagus moves food from the mouth to the cardiac sac, where it is mixed with digestive fluids. The softened food is then chewed by internal teeth in the gastric mill, and the pylorus filters the chewed food into three streams, one for absorption, one for further chewing by the gastric mill, and one for excretion. The stomatogastric nervous system lies on the surface of the stomach (red, fig. 1b) and contains almost all the neurons of the esophageal, cardiac sac, gastric mill, and pyloric CPG networks. These networks are composed almost exclusively of motor neurons, which both elicit muscle contraction and fulfill the rhythmogenic and pattern formation roles typically performed in other systems by a premotor interneuronal network. This happenstance has greatly facilitated network description, and in the lobster, Panulirus interruptus, the complete neuronal complements and synaptic connectivity diagrams are known for the cardiac sac, gastric mill, and pyloric networks (fig. 1c) [17-30]. Three notable characteristics of these networks are (1) the high degree of neuron interconnectivity in the gastric mill and pyloric networks, (2) the lack of a serial, hierarchical arrangement in the gastric mill and pyloric 


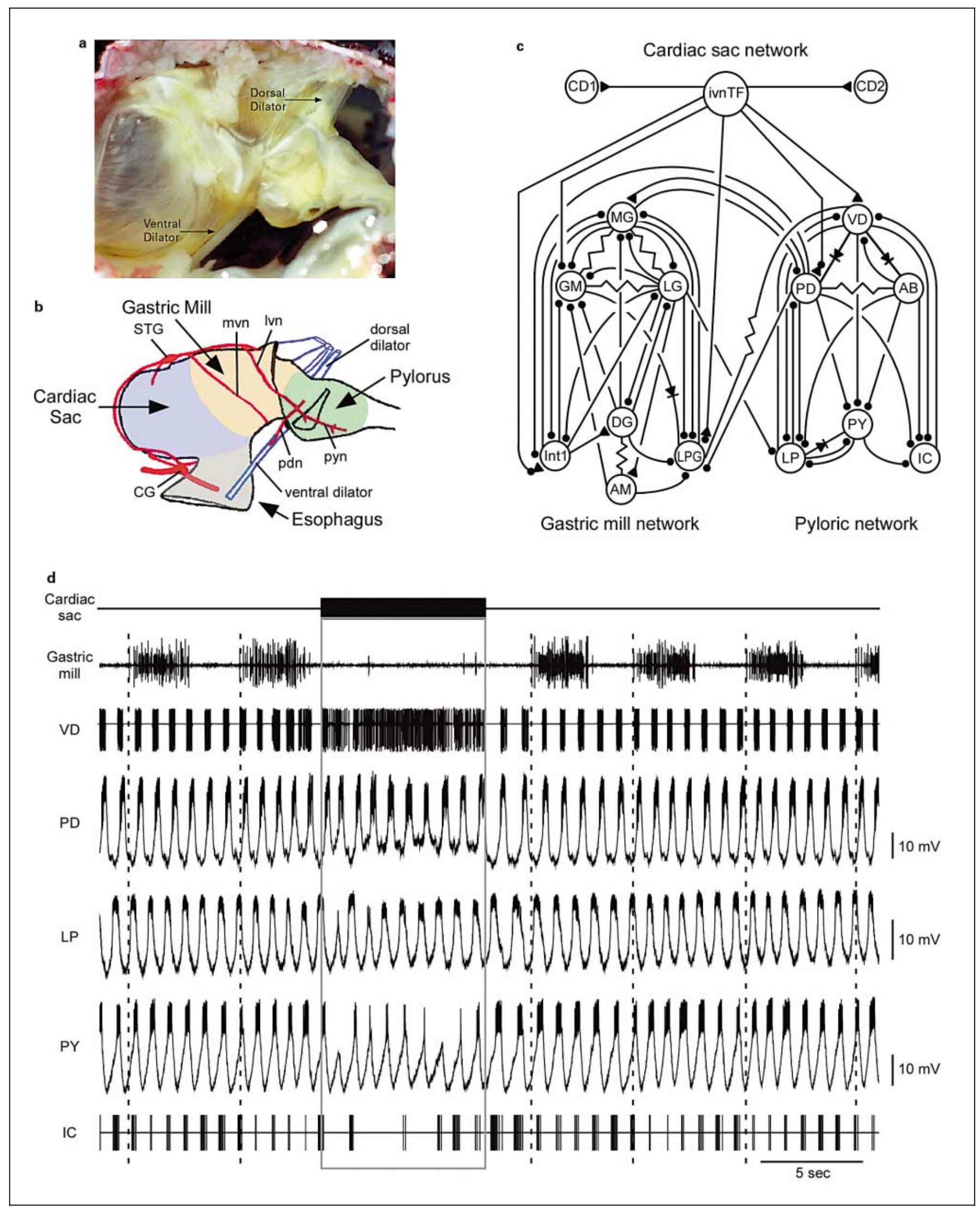


networks, and (3) the high degree of internetwork interactions.

These internetwork connections and the region's anatomical and functional relationships suggest that cardiac sac, gastric mill, and pylorus movements would be coordinated. Simultaneous recordings from the three networks support this expectation (fig. 1d). Cardiac sac neural output consists of long (2-8 s) simultaneous bursts of action potentials in all three cardiac sac network neurons (inferior ventricular nerve through fibers, cardiac dilator 1 , and cardiac dilator 2) approximately once per minute (one burst is shown schematically in the top trace; fig. 1d). The gastric mill is a faster (cycle period 5-10 s) multiphasic rhythm, i.e., the gastric mill neurons do not all fire together, but instead each gastric mill cycle consists of a sequence in which first some, and then other, and then still other gastric mill neurons fire, after which the sequence repeats. The trace shown is an extracellular recording of one gastric mill neuron type, the Gastric Mill (GM) neurons. The remaining traces show the activity of all five pyloric motor neuron types: Ventricular Dilator (VD), Pyloric Dilator (PD), Lateral Pyloric (LP), Pyloric (PY), and Inferior Cardiac (IC). The pyloric pattern is even faster (cycle period approximately $1 \mathrm{~s}$ ), and is also

Fig. 1. a A photograph of the lobster stomach. b A schematic showing the 4 regions of the stomach, the stomatogastric nervous system (red), and 2 pyloric muscles, the dorsal and ventral dilators. Nerve abbreviations: $\mathrm{pdn}=$ pyloric dilator; pyn $=$ pyloric lvn $=$ lateral ven tricular; $\mathrm{mvn}=$ medial ventricular. Ganglion abbreviations: $\mathrm{STG}=$ stomatogastric; $\mathrm{CG}=$ commissural. $\mathbf{c}$ Cardiac sac, gastric mill, and pyloric intra- and internetwork synaptic connectivity. Circles, triangles, and circles and triangles: inhibitory, excitatory, and mixed inhibitory and excitatory chemical synapses. Resistors: nonrectifying electrical coupling; diodes: rectifying electrical coupling. ivnTF $=$ Inferior ventricular nerve through fibers; $\mathrm{CD} 1, \mathrm{CD} 2=$ Cardiac Dilator 1 and 2; $\mathrm{MG}=$ Medial Gastric; $\mathrm{LG}=$ Lateral Gastric; Int $1=$ Interneuron 1; $\mathrm{AM}=$ Anterior Median. Modified from Thuma et al. [34]. d Cardiac sac, gastric mill, and pyloric network activity. Top trace: schematic of cardiac sac burst. The cardiac dilator (CD) 1 and CD2 neurons and the inferior ventricular nerve through fibers simultaneously fire a many second burst (solid bar) approximately every minute. Second trace: extracellular recording of GM neuron activity. Gastric mill bursts last for 2-3 s and gastric mill cycle period is approximately $5 \mathrm{~s}$. The gastric mill network neurons do not fire simultaneously, but instead with fixed phase relationships (e.g. the DG and AM neurons fire out of phase with the GM neurons, not shown). Traces 3-7: extracellular (VD, IC) and intracellular (PD, LP, $\mathrm{PY})$ recordings of pyloric network neurons. Pyloric cycle period is approximately $1 \mathrm{~s}$, and the pyloric neurons fire in a fixed order, PD first, then LP and IC, and then VD and PY. Note the strong alterations of gastric mill and pyloric activity during cardiac sac network bursts, and of pyloric activity during the gastric mill cycle. multiphasic. Not shown is the less well-defined esophageal rhythm, which has a 5- to 10-second cycle period.

During cardiac sac bursts (fig. 1d: grey rectangle), the gastric mill and pyloric neural outputs are altered: the gastric mill pauses, VD and PD neuron activity increases, and PY and IC neuron activity decreases [27, 31]. Pyloric activity is also altered during each gastric mill cycle (fig. 1d: delineated by the dashed lines): PY neuron activity decreases just before, and IC neuron activity just after, each GM neuron burst [23, 32]. Not visible on this time scale is a decrease in PD neuron activity that occurs during each GM neuron interburst interval. These changes are sufficient that, due to slow integrative properties in the muscles, some pyloric muscles primarily express cardiac sac and gastric mill motor patterns even though no cardiac sac or gastric mill motor neurons innervate the muscles (see below) [33, 34]. In other species, these interactions are sufficient that an integer number of pyloric cycles occurs in each gastric mill cycle $[35,36]$. As such, although the cardiac sac, gastric mill, and pyloric networks are distinct (each network's neurons cycle as separate sets with different cycle periods), and are often studied in isolation, the stomatogastric nervous system is a set of centrally interacting networks that produce a coordinated set of stomach motor patterns.

\section{Multifunctional Networks with Flexible Boundaries}

In response to the application of neuromodulatory substances or stimulation of central or sensory inputs, the stomatogastric nervous system produces an extraordinarily wide range of neural outputs by (1) individual neural networks producing multiple outputs [37-54], (2) neurons switching from one network to another [55-60], and (3) networks fusing into larger, aggregate networks [61-63]. The ability of individual networks to produce multiple outputs is of two types. First, analogous to fast and slow swimming, the networks can produce the 'same' pattern at different cycle periods (i.e., normalized to cycle period, the delays between different neuron bursts, and burst durations are constant) [64]. Second, single networks can produce different neural patterns in which the relative delays and burst durations change (analogous to changing swimming strokes). In the example shown in figure 2a, proctolin was applied to the pyloric network, which greatly increased LP neuron burst duration. Figure $2 b$ shows an example of a neuron switching between neural networks. In the first panel (gastric mill network silent), the lateral posterior gastric (LPG) neuron fired once every PD neuron burst. However, when the gastric mill network was active, the LPG neuron instead fired in time with the dor- 


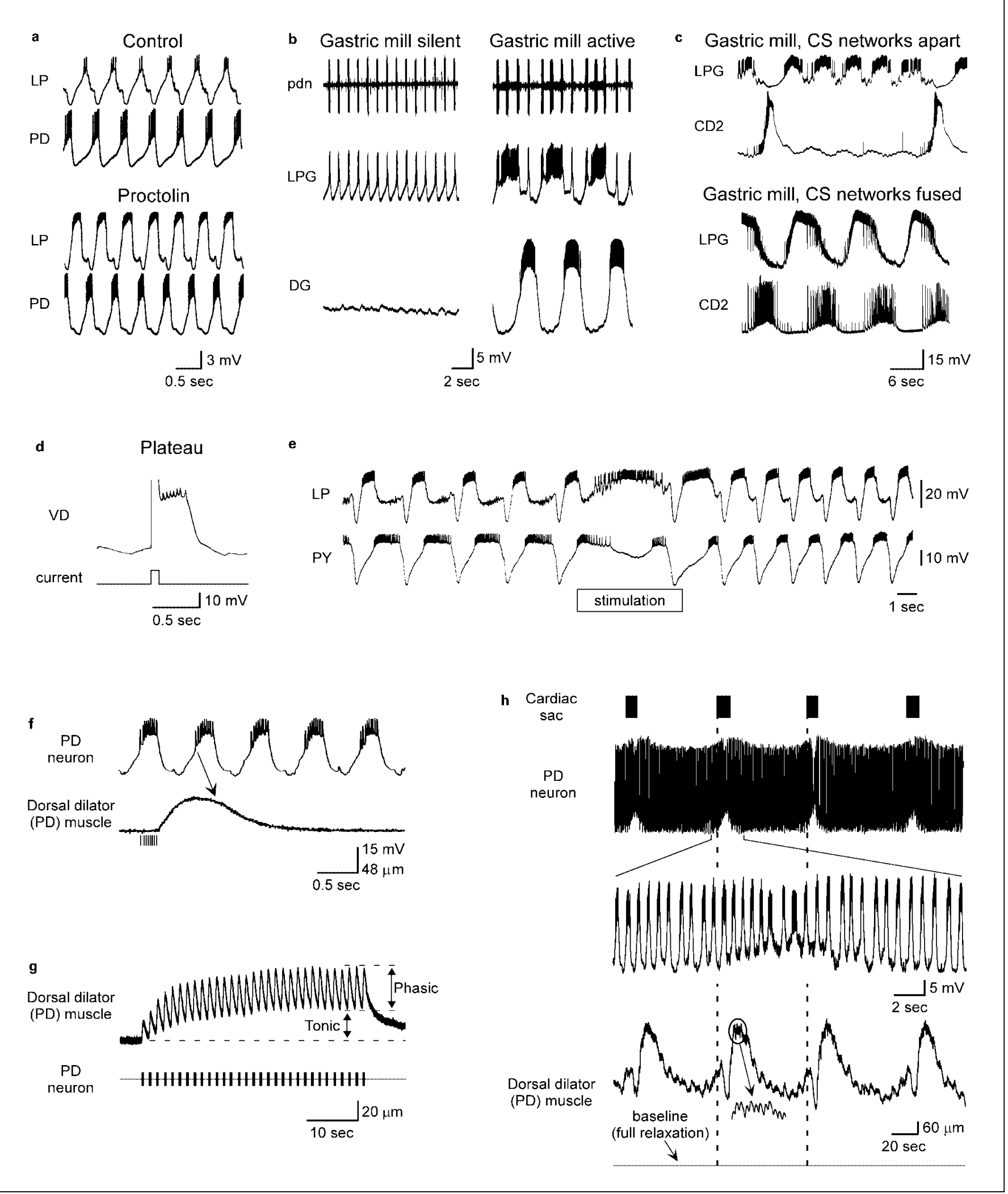


sal gastric (DG) neuron (and hence also the rest of the gastric mill network). Figure $2 \mathrm{c}$ shows an example of gastric mill and cardiac sac network fusion - in the top panel, the two networks are cycling independently, whereas in the bottom panel, the neurons of both networks cycle together in a new, conjoint pattern. Note that the cycle period of the new pattern is different from that of either the gastric mill or cardiac sac networks when apart, and thus this is not an example of the neurons of one network joining another.

\section{Mechanisms Supporting Motor Pattern Generation and Pattern Flexibility}

The mechanisms underlying network rhythmicity and neuron phase relationships are best understood in the pyloric network. All network synapses are inhibitory. Although the neurons fire bursts of spikes that travel to their extraganglionic targets, intranetwork synapses are

Fig. 2. a Stomatogastric (STG) network modulation. Proctolin induces the LP neuron to fire longer, higher-frequency bursts of spikes. Modified from Marder et al. [194]. b Neuron switching. When the gastric mill is silent, the LPG neuron fires with the pyloric pattern [pyloric dilator (pdn) extracellular trace]. When the gastric mill is active (note DG neuron cycling), the LPG neuron fires with the gastric mill pattern. Modified from Weimann et al. [59]. c Network fusion. In control saline, the gastric mill (LPG neuron) and cardiac sac [cardiac dilator (CD) 2 neuron] networks cycle independently. The modulatory peptide red pigment concentrating hormone induces the networks to fuse. Modified from Dickinson et al. [61]. $\mathrm{CS}=$ Cardiac sac. $\mathbf{d}$ Injecting a brief depolarizing current pulse triggers a plateau in the VD neuron. Modified from Hooper and Moulins [56]. e Stimulation (rectangle) of a sensory receptor activated by gastric mill movement disrupts pyloric cycling during the stimulation, and induces a long-lasting increase in pyloric cycle frequency after it. Modified from Katz and Harris-Warrick [46]. f-h Slow muscle properties allow muscles to express the motor patterns of noninnervating neurons. $f$ The dorsal dilator muscle was isolated from its innervating PD neuron by cutting the motor nerve, and the muscle induced to contract by stimulating the motor nerve (vertical bars under muscle trace) in a pattern identical to the spikes in the first PD neuron burst (top trace). If the innervation of the muscle had been intact, the next PD neuron burst (arrow) would have reached the muscle before it had fully relaxed. $\mathbf{g}$ When the motor nerve is stimulated with rhythmic shock bursts (rectangles, bottom trace) mimicking motor neuron input, the contractions temporally summate. $\mathbf{h}$ When driven by real PD neuron bursts (top trace; second trace shows time expansion during cardiac sac network burst), the alterations in PD neuron firing during cardiac sac bursts (see also trace 4, fig. 1d) cause the tonic contraction component of the muscle to vary in cardiac sac time. The primary rhythmic output of the muscle is therefore cardiac sac timed; the inset shows the very small contractions induced by the neuron (PD) that actually innervates the muscle. All panels modified from Morris et al. [33].

Crustacean Motor Pattern Generator

Networks graded and correctly timed network oscillations continue even in tetrodotoxin (TTX) [65-69]. When the network is receiving modulatory input from higher centers, its rhythmicity is primarily due to endogenous bursting ability in the Anterior Burster (AB) neuron (although under these conditions, all pyloric neurons are endogenous bursters [70], the $\mathrm{AB}$ neuron cycles most rapidly and entrains the other neurons to its period). The AB and PD neurons are electrically coupled and therefore burst together. These neurons inhibit all other pyloric neurons. After the $\mathrm{AB} /$ PD neuron burst ends, these other neurons fire because of two endogenous characteristics, plateau properties [71, 72] and postinhibitory rebound. Neurons that plateau have, in addition to a stable hyperpolarized rest membrane potential, a semistable suprathreshold depolarized membrane potential. The neurons can be triggered to move from the rest to the depolarized plateau by brief depolarizations (fig. 2d). Postinhibitory rebound is a property in which inhibition below rest activates hyperpolarization-activated depolarizing conductances, and thus after inhibition, the neuron depolarizes above rest. As a result of these two characteristics, the neurons inhibited by the $\mathrm{AB} / \mathrm{PD}$ neuron ensemble depolarize above plateau threshold after the AB/PD burst, and thus themselves fire a burst. The phase relationships among these 'follower' neurons (the LP and IC neurons fire first, and then the PY and VD neurons) result from their differing cellular properties (the PY neurons rebound more slowly than the LP and IC neurons [73]), and the synaptic connectivity of the network (the LP and IC neurons inhibit the PY and VD neurons).

Although this explanation is adequate for some network conditions, it is not complete. For example, the network continues to produce a rapid rhythmic output even if the $\mathrm{AB}$ neuron is killed. Network rhythmicity in this case is unlikely to be due to the endogenous bursting abilities of the other neurons, as their inherent cycle periods are considerably longer (several seconds) than the 1-second cycle period of the network. In this situation, a different method of rhythmogenesis, half-center oscillation [74], is likely responsible. Key to this mechanism is mutual inhibition between neurons, e.g. the LP and PD neurons. For neurons with postinhibitory rebound and plateau properties, this synaptic arrangement can induce rhythmogenesis as follows. If the PD neuron is induced to plateau, it will inhibit the LP neuron. After the PD neuron plateau ends, the LP neuron will plateau and fire due to postinhibitory rebound. This inhibits the PD neuron, which therefore rebounds and fires after the LP neuron burst ends, and the cycle continues. 
In the animal, the $\mathrm{AB}$ neuron is presumably never dead, and these multiple rhythmogenic mechanisms therefore presumably do not exist as a fail-safe redundancy to maintain pyloric activity in the unlikely event of $A B$ neuron ablation. They instead presumably reflect, as also does what a priori appears to be the 'overly' complex synaptic connectivity of the network, the ability of the network to produce multiple patterns, and of its neurons to move between networks. Investigation of the mechanisms underlying these properties supports this contention. First, the changes in network activity induced by modulator application often cannot be explained solely by the changes the modulator induces in the neurons it directly affects. Instead, due to the dense synaptic connectivity of the network, changes in directly affected neurons alter the activity of nondirectly affected neurons, and the response of directly affected neurons is altered by their interactions with nondirectly affected neurons [44]. The response of the network is thus distributed across the network, and cannot be understood except by considering the network as a whole.

Second, this distributed action is also seen in network switches. For instance, cardiac sac network activation by a stomatogastric sensory input switches the VD neuron to the cardiac sac network (because the neuron loses its plateau properties, and so fires when the inferior ventricular nerve through fibers of the cardiac sac network fire - see figure $1 \mathrm{c}$ - but not after each $\mathrm{AB} / \mathrm{PD}$ neuron inhibition). Input stimulation also changes IC neuron activity, but these changes occur solely due to the absence of VD neuron input to the IC neuron [56]. Third, examining the effects of VD or LP neuron removal from the network shows that in control saline, most of the synapses these neurons make have inconsistent or no effects on the firing of other pyloric neurons [75]. These synapses presumably did not evolve for no reason, and an attractive hypothesis is that they help generate network activity under other modulatory conditions. Fourth, modulatory inputs to stomatogastric networks can receive presynaptic inhibition from neurons of the network the inputs modulate [76-79]. As a consequence, although the inputs may fire very long bursts or even tonically, their input to the network will occur with the cycle period of the network (because the long bursts are inhibited at the input synapses by the presynaptic inhibition). As such, the synaptic connectivity and cellular properties of the stomatogastric networks, their interconnections, and their inputs cannot be understood except in the context of these being multifunctional networks with flexible boundaries.
Another extremely important point about how the pyloric network functions is its history dependence. History dependence arises in this network via two mechanisms. The first is that some cellular properties, notably the time it takes for neurons to reach plateau after inhibition, vary as a function of the cycle period and duration of the inhibitions the neurons receive. This has been best investigated with the PY neurons, in which rebound time increases with cycle period [80]. The delays between neuron bursts must increase if the 'same' pattern is to be produced as network cycle period changes, and this property thus presumably partially underlies the ability of the pyloric network to produce the 'same' pattern at different cycle periods. This shifting of rebound delay with cycle period, however, is only half that necessary to explain the observed data. The rest of this ability likely stems from a history dependence of synaptic strength on inhibition, cycle period and duration [81-83]. Both of these historydependent processes vary slowly (over several seconds), and thus network activity at any time is a function of an average of network activity for several prior cycles. Activity in the pyloric network (and presumably the other stomatogastric networks) is thus not only distributed across the component neurons and synapses of the network, but also across time.

\section{Peripheral Integration via Sensory Feedback}

The lobster stomach is richly endowed with sensory neurons [84], but in most cases, their function is unknown. Two systems that have been investigated function, in part, to allow movements in one stomach region to alter the movements of other regions. These data thus support the impression made by the extensive internetwork synaptic connections, and coordinated changes in network activity, that coordinated stomach movements are functionally important. The first sensory pathway is triggered by pyloric distention, but induces cardiac sac network bursts [85], which result in cardiac sac dilation. An attractive hypothesis is that this pathway serves to transfer food from the pylorus to the gastric mill and cardiac sac if the pylorus becomes excessively full. The second is triggered by gastric mill movements [46, 86, 87]. One target of this input is the gastric mill network itself, for which it presumably serves as a typical, cycle-by-cycle proprioceptive feedback loop. However, this input also targets the pyloric network. Due to the long duration movements of the gastric mill, this receptor fires long bursts lasting for several pyloric cycles, during which the pyloric cycling is disrupted (fig. 2e). Subsequent to the bursts, pyloric cycle frequency increases for up to a min- 
ute. The input thus serves to both coordinate the two networks and modulate pyloric activity.

\section{Peripheral Integration via Slow Muscle Properties}

Many stomatogastric muscles contract and relax very slowly - some taking many seconds to fully relax. For the slow cardiac sac and gastric mill networks, this is not a concern, as even very slow muscles could still fully relax between one burst and the next of their innervating neuron. The muscles innervated by the rapid pyloric network, however, cannot fully relax between neuron bursts (fig. 2f), and their contractions therefore temporally summate (fig. 2g). If the pyloric network were not slowly modified in time with the gastric mill and cardiac sac rhythms, pyloric muscle contractions would thus, once the temporal summation was finished, consist of phasic contractions in time with the pyloric bursts riding on a sustained, tonic contraction (fig. 2g) [88]. However, pyloric activity is modified in gastric mill and cardiac sac time, and the tonic contraction component of the slow muscles varies with these modifications [33, 34]. These variations can be the primary rhythmic motor output of some slow muscles (fig. $2 \mathrm{~h}$ ), even though no gastric mill or cardiac sac motor neuron innervates them.

\section{Gill Ventilation}

\section{Overview}

Ventilation in decapod crustacea is produced by rhythmic dorsoventral movements of the scaphognathite (SG) of the second maxilla, which pumps water through the branchial chamber and over the gills. Five depressor and levator muscles control SG movement [89]. SG movement can pump water in either of two directions, corresponding to forward and reverse ventilation. In forward ventilation, water enters at the base of the legs and exits via anterior exhalent channels under the antennae. Forward pumping is the prevalent mode in Carcinus maenas. In reverse ventilation, the recruitment sequence of levator and depressor muscle subgroups is changed such that water enters through the anterior channels and exits at the base of the legs. The forward to reverse transition always occurs between the depressor and levator bursts, at which time there is nearly equal pressure between the pumping chamber and the branchial chamber [90]. Motor program switching at this time would thus minimize backwash of fluid into the pumping chamber, which could mechanically perturb the SG blade.

Crustacean Motor Pattern Generator

Networks

\section{The Ventilatory CPG Is Composed of Interneurons}

\section{and Motor Neurons}

When the thoracic ganglion and appropriate nerves are removed from the animal, spontaneous rhythmic motor neuron spike bursts corresponding to forward and reverse ventilation are observed (fig. 3a, b). As in the animal, forward ventilation is most common, with bouts of reverse ventilation, and ventilatory pauses, occurring infrequently. Unlike the stomatogastric system, the CPG contains large numbers of premotor interneurons. Although originally thought to be a single endogenously oscillating nonspiking neuron [91], the interneuronal ventilatory CPG was later shown to consist of at least two [92], and is now known in the crab, $C$. maenas, to consist of 8 , nonspiking interneurons [CPG interneurons (CPGi) 1-8] [93]. Figure $3 \mathrm{c}$ shows extracellular recordings of the activity of all the ventilatory motor neurons, and intracellular recordings from a depressor motorneuron and one CPGi. The network displays all the defining characteristics of a true CPG. The interneurons exhibit large-amplitude (10$35 \mathrm{mV}$ ) membrane potential oscillations during forward and reverse ventilation, and no oscillations during pauses. In the in vitro preparation, no sensory feedback loops are present, and the interneurons do not receive phasic nonCPG descending input. Injecting intracellular current pulses into any interneuron can reset the rhythm.

All the interneurons are restricted to a single hemiganglion, there is one (and only one) of each interneuron type per hemiganglion, and intracellular current injection affects only the activity of the hemiganglion containing the interneuron. These data indicate that separate CPGs produce the left and right SG ventilatory patterns [93], and are consistent with data showing that the left and right ventilatory rhythms are generated and controlled independently [90, 91, 94]. Moreover, it reinforces the hypothesis that the loose phase coupling observed between bilateral CPGs [94] is mediated by the nonspiking frequency modulating interneurons (FMis; see below) [95] rather than midline crossing CPGi interconnections.

The interneuron synaptic connectivity pattern is unknown because the primary method of demonstrating synapses, one-for-one constant-delay matching of postsynaptic potential and presynaptic spikes, is unavailable in a network of nonspiking neurons. However, neuron membrane potential trajectories, data from current injection experiments (to see if neuron hyperpolarizations and depolarizations reverse), and voltage clamp recordings showing appropriately timed inward and outward currents suggest that the interneurons receive both excitatory and inhibitory inputs from the rest of the network.

Neurosignals 2004;13:50-69 


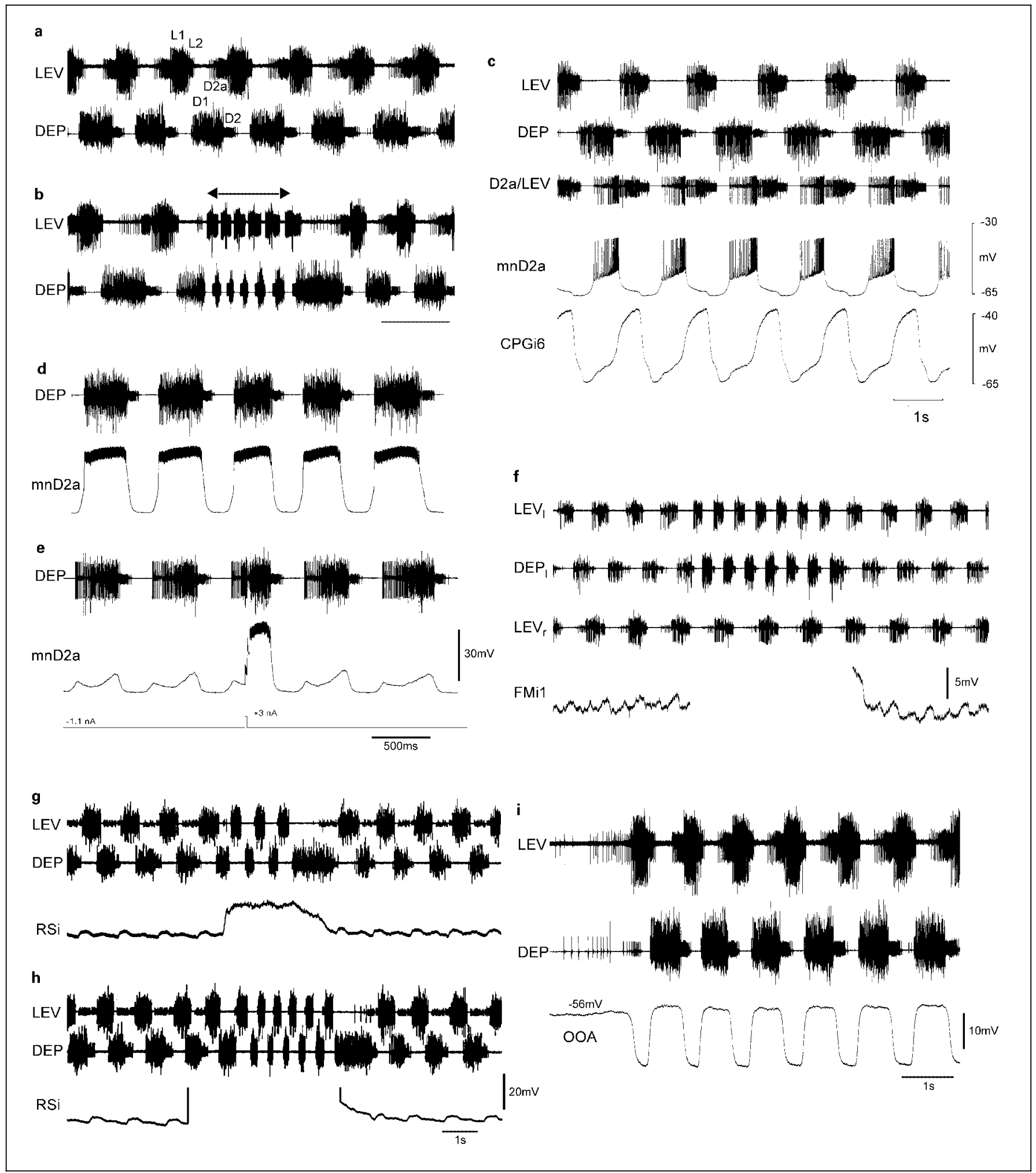


Whether network rhythmicity arises from endogenous oscillatory properties or a nonspiking equivalent of halfcenter oscillation is also unknown. Current injection into single interneurons does not reliably elicit excitatory or inhibitory responses from a single or groups of motor neurons, suggesting that motor neurons receive input from multiple CPGis. Sustained CPGi hyperpolarization can, however, excite some ventilatory motor neurons, which may indicate that, as has been demonstrated in other arthropod nervous systems $[67,96]$, the CPGis continuously release transmitter in a graded manner. Current pulse injection into the motor neurons also resets the rhythm, and thus these neurons are also part of the ventilatory CPG, but the synaptic connectivity among them, and to the interneurons, is again unknown.

\section{Motor Neuron Properties}

Ventilatory motor neurons exhibit large-amplitude $(15-30 \mathrm{mV})$ membrane potential oscillations (fig. 3c,

Fig. 3. The crustacean ventilatory system. All records from isolated ganglion preparations in C. maenas. a, b Extracellular recordings of ventilatory motor output during forward and reverse ventilation. The SG is driven by levator (L) and depressor (D) motor neurons, each divided into two subgroups, L1 and L2, D1 and D2. a During forward ventilation, the muscle recruitment sequence is L1-L2-D1D2 [89]. b In reverse ventilation (arrow), ventilatory cycle frequency increases and the muscle recruitment sequence is D2-D1-L2-L1. c Extracellular recording of all ventilatory motor neurons (top 3 traces) and intracellular recordings from a motor neuron innervating muscle D2a (mnD2a) and a nonspiking CPGi, CPGi6. d, e Plateau potentials in ventilatory motor neurons. d Extracellular recording of depressor (D) motor neuron activity and intracellular recording from a $\mathrm{D} 1$ motor neuron during forward ventilation. $\mathrm{mnD} 2 \mathrm{a}=$ Motor neuron innervating muscle D2a. e Injection of a 1.1-nA hyperpolarizing current into the motor neuron decreases its oscillation amplitude to a maximum of $9 \mathrm{mV}$. Injection of a $20-\mathrm{ms}$ current pulse in addition to the sustained hyperpolarizing current (net current amplitude $+3 \mathrm{nA}$ ) triggers a plateau potential. This resultant spike burst is terminated at its normal phase by synaptic inhibition from the ventilatory CPG. f Extracellular recordings of left (top 2 traces) and right (third trace) ventilation CPGs and intracellular recording from left FMi1. FMi1 depolarization ( $3 \mathrm{nA})$ increases ventilation frequency on the left side but not on the right. $\mathbf{g}, \mathbf{h}$ Reversal switch interneuron RSi1. $\mathbf{g}$ RSil depolarizes during a spontaneous switch to reverse ventilation and repolarizes on return to forward ventilation. $\mathbf{h}$ Depolarizing RSi1 $(2.5 \mathrm{nA})$ during forward ventilation initiates reverse ventilation, which persists for the duration of the current step. i Ventilatory gating of sensory input. Intracellular recording from an oval organ afferent (OOA). During a ventilatory pause, the membrane potential of the afferent is unchanging. Ventilatory activity is associated with a large amplitude hyperpolarizing oscillation in OOA membrane potential. trace 4; fig. 3d, trace 2). Motor neuron bursting had initially been attributed to cyclic inhibition from the ventilatory CPG onto neurons that otherwise would fire tonically $[97,98]$. However, a subsequent study showed that the motor neurons possess plateau properties [99]. When ventilatory motor neurons are hyperpolarized by intracellular current injection, the large-amplitude membrane potential oscillations are abolished, and only small $(5-8 \mathrm{mV})$ oscillations in phase with the motor pattern remain. Injecting a brief depolarizing current pulse induces a large amplitude plateau potential and a burst of action potentials that lasts until it is terminated by inhibitory input from the rest of the network (fig. 3e, bottom trace). Injecting brief hyperpolarizing current pulses during the bursts of normally cycling motor neurons, however, does not terminate the plateaus as it should if only the plateau supports the bursts. It is thus likely the motor neurons also receive excitatory synaptic drive during their bursts. Plateau potentials are found in all motor neurons of both the forward and reverse populations.

Ventilatory motor neuron burst endings are therefore likely due to cyclic synaptic inhibition from the ventilatory CPG, as has been proposed previously [97], whereas burst beginnings are due to plateau potentials triggered either by postinhibitory rebound or excitatory input from the rest of the network. However, the presence of a plateau potential removes the need for the CPG to supply excitatory drive to the motor neurons throughout the burst duration.

\section{Starting, Stopping, and Changing the Frequency of Ventilatory Rhythms}

Descending fibers that stop, start, and alter ventilation period are present in nerves connecting the brain and the thoracic ganglia [94]. Three FMis (FMi1-3) have been identified that have somata and processes in the subesophageal ganglion and are apparently intercalated between the descending fibers and the ventilatory CPG. Changing FMi membrane potential by intracellular current injection can start and stop ventilation, and alter ventilation frequency in a graded manner across the physiologically observed range [95]. All three FMis project bilaterally into the left and right CPG neuropil, but changing FMil membrane potential alters only the rhythm of the CPG ipsilateral to its soma (fig. 3f). FMi2 and FMi3, alternatively, modulate the rhythm of both CPGs. Ventilation frequency increases with FMil depolarization, and decreases with FMil hyperpolarization; the reverse is true of FMi2 and FMi3. The FMis receive cyclic synaptic input in phase with the ventilatory rhythm and thus cycle 
with it. This input is of a polarity (excitatory for FMi1, inhibitory for FMi2 and FMi3) that would act as a positive feedback loop on ventilatory cycle frequency. Injecting brief current pulses into any FMi resets the rhythm, and thus these neurons are part of the CPG network.

The changes in CPG neuron or synaptic properties that cause the rhythm to start, stop, and change frequency are little known. An important component of rhythm stopping, however, is cessation of motor neuron plateau potential ability [99]. Plateau property expression thus depends on influences from the ventilatory CPG or from descending inputs to the motor neurons parallel to, or the same as, those that activate the CPG. Modulation of plateau expression has been observed in several other invertebrate and vertebrate motor systems [56, 100-105].

\section{Ventilatory Rhythms Maintain Phase as Their Cycle Frequency Changes}

Changing cycle period raises the difficulty of whether the 'same' pattern is produced at different cycle periods. That is, if neuron B fires $2 \mathrm{~s}$ after neuron A when the cycle period is $4 \mathrm{~s}$, neuron $B$ begins to fire half way through the pattern. If neuron $\mathrm{B}$ continues to fire $2 \mathrm{~s}$ after neuron $\mathrm{A}$ when the period is $3 \mathrm{~s}$, neuron $\mathrm{B}$ now begins to fire three quarters through the pattern (and thus the slow and fast patterns are not the 'same' in that, were a plot of the slow pattern reduced along the time axis by $25 \%$, the two patterns would not overlay). Even more extremely, if the period decreased to $1 \mathrm{~s}$, neuron B could not fire at all. Systems that maintain constant time delays between events in the motor pattern thus produce motor outputs in which phase (delay between events divided by period) varies with cycle frequency, whereas systems that maintain phase must increase or decrease the time between events as cycle frequency changes. Both constant delay and constant phase-maintaining systems are observed [64, 106-112].

Ventilation occurs in vivo at frequencies of 40 to over 300 cycles per minute, an 8 -fold range $[113,114]$. Cinematography of SG movements is unavailable, and it is thus unclear if motor pattern movements maintain phase (that is, that each movement proportionally changes) as cycle period is altered across this range. However, in vitro recordings show that motor neuron output maintains phase over a 7-fold range of network cycle period [115]. If movement faithfully reflects motor neuron activity in this system, movements would thus be expected to maintain phase. Phase maintenance over this large (300-2,100 ms) period range requires that neural pattern time delays change up to $800 \mathrm{~ms}$. Intracellular recordings show that motor neuron membrane potential trajectory changes little as cycle period is altered. However, recordings from the interneurons reveal that the rise and fall slopes of their membrane potential oscillations change proportionally with cycle period changes [115].

These data imply that phase maintenance is critical to gill bailer function. Comparison of phase-maintaining and nonphase-maintaining motor patterns suggests a possible reason. Nonphase-maintaining motor patterns (e.g. walking) often have distinct power vs. return strokes; phase is not maintained because at all cycle periods the return stroke is about as rapid as it can be, and thus period can only change by changing return stroke duration. Phase-maintaining motor patterns (e.g. airstepping) generally do not have clearly differentiated power and return phases. The SG moves as follows. Beginning with the anterior tip of the blade being levated and the posterior depressed, the anterior tip then depresses and the posterior tip levates, after which the anterior again levates and the posterior depresses [89]. Pumping occurs both when the anterior depresses and the posterior levates, and when the anterior levates and the posterior depresses, and thus the pattern does not have distinct power vs. return strokes [116]. Pump function is well maintained as cycle period changes - ventilation volume and branchial pressure gradient are exactly proportional to ventilation frequency [117], and pump efficiency remains a constant $85 \%$ over a wide range of ventilatory frequencies [118].

Without a detailed understanding of SG biomechanics, it is impossible to prove that motor neuron phase maintenance is required for this high maintenance of pump function as cycle period changes. Consideration of SG anatomy and neuromuscular control, however, suggests this may be the case. The SG is flexible, and the anterior and posterior tips are independently controlled. Thus (although it never occurs in the animal), if motor neuron phase relationships were not maintained, the anterior tip, for instance, could depress long before the posterior tip levated, which would destroy pumping. Ventilatory phase maintenance may thus serve two purposes. First, tight maintenance at blade tip transitions causes one tip to start its transition immediately after the opposite tip is maximally levated or depressed. This maximizes expelled fluid and minimizes the time that both tips are in the same (levated or depressed) position. Second, phase maintenance during the remainder of the motor pattern may produce smooth, coordinated blade movements, preventing discontinuities in SG movement that might decrease pump efficiency. 


\section{Switching between Forward and Reverse Ventilation}

A major change in reverse ventilation is that the motor neurons that innervate the L2 and D2 muscles, and which are active during forward ventilation, stop firing, and the muscles are driven instead by a set of reversal specific motor neurons [89, 119]. These 'reversal' motor neurons are cyclically inhibited during forward ventilation but do not fire; their recruitment in reverse ventilation is apparently due to a tonic depolarizing drive during this time. Reversal motor neuron depolarization by intracellular current during forward ventilation results in these neurons firing bursts at the phase of the ventilatory cycle appropriate for reverse ventilation. A neuron switch also occurs on the CPGi level, the peak-to-peak amplitude of CPGi1 increases, and that of CPGi5 decreases, during reverse ventilation. The decrease in CPGi5 amplitude is sufficient that the neuron likely stops releasing transmitter, and is thus no longer a functional element of the ventilatory CPG. Whether the changes in CPGil are also large enough to constitute a switch (with it functioning with the CPG only during reversed ventilation) is not clear, but its input to the CPG is clearly greater during reversed ventilation. The oscillatory amplitudes of the other 6 CPGis are unchanged in forward and reverse ventilation.

A reversal switch interneuron (RSi1) that depolarizes when ventilation reverses, and remains depolarized during reverse ventilation, has been identified (fig. 3g) [120]. RSil depolarization by current injection reverses ventilation for the duration of the step (fig. 3h), and RSil hyperpolarization during reverse ventilation terminates the reverse motor program. Brief depolarizing current pulses injected into RSil reset the forward rhythm, but only if applied at certain phases in the pattern, suggesting that RSil has access to the ventilatory CPG during only specific portions of the cycle. Hyperpolarizing pulses never reset forward ventilation, suggesting that RSil is not a component of the CPG during forward ventilation. An attractive hypothesis is that RSil causes reversal by inhibiting the forward ventilation L2 and D2 motor neurons and CPGi5 and exciting the reversal-specific motor neurons and CPGi1. Anterior branches of RSil are close to where the FMis span the thoracic ganglion, and FMi2 is tonically hyperpolarized during reversed ventilation. The posterior branch of RSil could provide a mechanism for the correlation between the onset of reverse ventilation and tachycardia [121, 122], as the cardiac accelerator and inhibitor neurons lie posterior to the ventilatory neuropil.

\section{Gating of Sensory Input to the Ventilatory $C P G$}

The only SG proprioceptor is the oval organ, located adjacent to the SG flexion axis [123]. The oval organ is innervated by three afferent neurons with somata in the thoracic ganglion; depending on the species, the afferents can be either spiking (lobster [124]) or nonspiking (crab [125]). Depolarizing or hyperpolarizing current pulses injected into a single afferent reset the ventilatory rhythm. Imposed SG movement in the lobster elicits afferent action potentials during both levation and depression [123], and pressure recordings in intact crab branchial chambers reveal two negative pressure pulses per cycle [116]. Although this would seem to indicate that oval organ afferent input would reach the ventilatory CPG twice per cycle, intracellular recordings from crab oval organs show that afferent central processes are inhibited in phase with the ventilatory motor pattern (fig. 3i). The inhibition blocks afferent input to the ventilatory CPG for approximately $50 \%$ of the cycle period, which likely includes one of the two pressure pulses per cycle [89]. This restriction of sensory input to one phase of the motor pattern may prevent sensory input from reaching the CPG at an inappropriate time, and may be analogous to primary afferent depolarization [126], which is also believed to modulate reflex pathways so as to prevent inappropriately timed input during rhythmic motor pattern generation [127-129].

\section{Cardiac CPG}

\section{Overview}

The cardiac ganglion drives the heart in a very stereotyped and stable rhythm [130]. In most crustacea, the ganglion contains 9 neurons (range, 6-16) located in or on the heart. The neurons are functionally and anatomically subdivided into 4 small posterior interneurons and 5 large anterior heart motor neurons (fig. 4a). The dendrites of both neuron types extend out of the ganglion onto the surface of the heart. The large cells have a peripheral spikeinitiating zone, and may have multiple spike-initiating zones. Bursts begin with a high firing rate that decreases during the burst, and have only a small number of spikes. For each neuron, the temporal pattern of individual action potentials in the bursts is highly reproducible across cycles [131].

\section{Network Synaptic Connectivity}

Each small cell makes excitatory glutamatergic synapses with all large neurons [132]; both axon-axonal and 


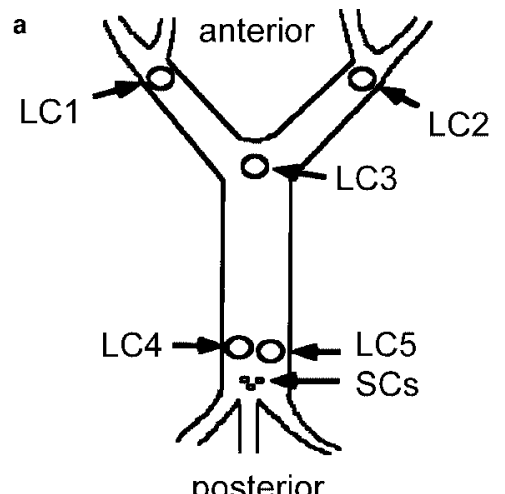

posterior

b

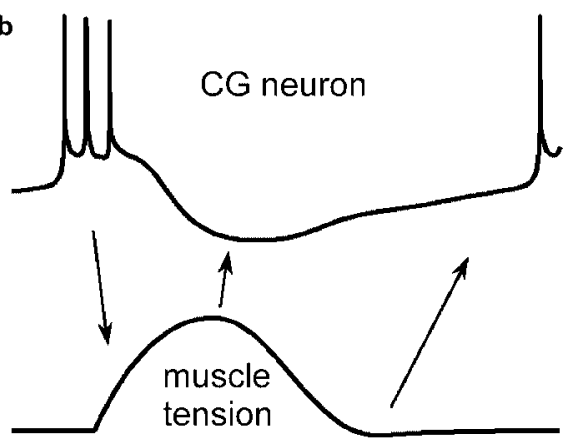

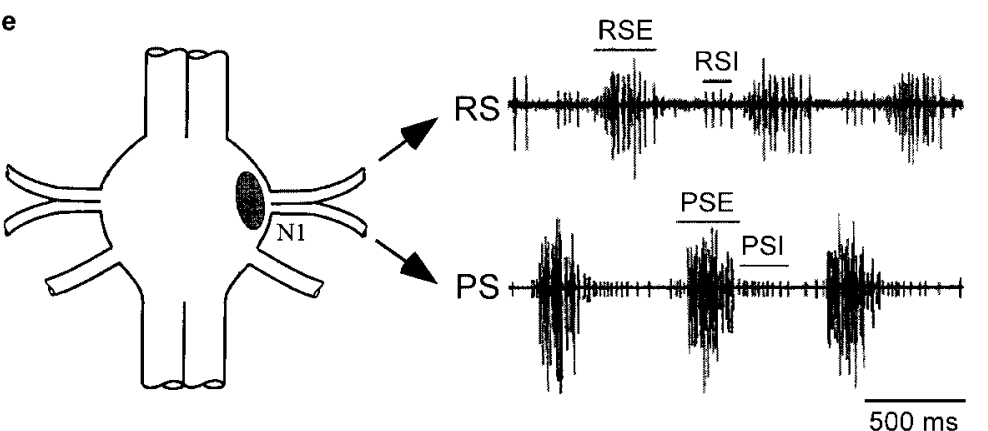

f

PSE2

PSE3

PSE4

PSE5

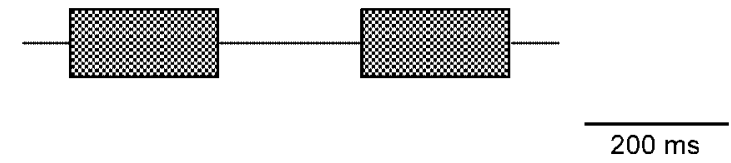

$\mathbf{g}$

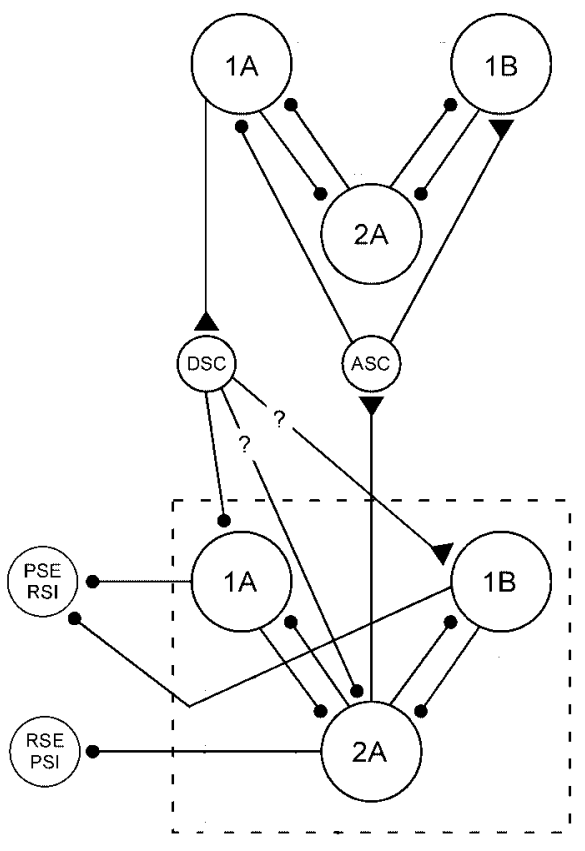


axosomatic synapses are present [133]. All cardiac neurons are also electrically coupled [134, 135]. These synapses significantly attenuate action potentials, but transmit slow potentials (pacemaker and driver potentials) throughout the network. No synaptic potentials have been observed in small cells, but the possibility of graded synaptic input has not been tested. Nitric oxide has been suggested to be an intrinsic neuromodulator of the network [136].

\section{Rhythmogenesis in vivo May Involve a Proprioceptive Feedback Loop}

An intact heart that is not mechanically stressed by suspension via ligaments or stretched by internal perfusion pressure does not generate rhythmic movements [137], and cardiac neurons in such quiescent hearts do not fire rhythmic spike bursts [131]. However, in situ preparations where the heart is stretched will generate a rhythm, as do mechanically stimulated intact preparations [131, 137]. These data suggest that proprioceptive feedback (via cardiac neuron dendrites on the heart) from CPGinduced movements help maintain CPG activity. Direct evidence of this is provided by data showing that mechan-

Fig. 4. Cardiac ganglion and swimmeret systems. a Schematic of C. maenas cardiac ganglion. Cells numbered using the nomenclature of Alexandrowicz [145]. LC = Large cell; SC = small cell. $\mathbf{b}$ Schematic of cardiac ganglion (CG) neuron membrane potential and heart tension. Cardiac ganglion motor neuron (large-cell) firing increases heart tension. The increase in tension hyperpolarizes the neuron, which may assist burst termination and increase neuron after-burst hyperpolarization. When the heart relaxes, the neuron undergoes postinhibitory rebound, which may advance the following burst. Modified from Sakurai and Wilkens [138]. c Driver potential in a large cell. Modified from Benson and Cooke [195]. d Schematic of the generation of pacemaker and driver potentials in the cardiac ganglion. EPSPs $=$ Excitatory postsynaptic potentials. Modified from Benson and Cooke [195]. e Left: diagram of an abdominal ganglion showing the first pair of segmental nerves (N1), which provide the sole innervation of the swimmerets in that segment. Shaded region denotes swimmeret neuropil. Each N1 divides into anterior and posterior branches containing return-stroke (RS) and power-stroke (PS) motor axons. Right: extracellular recordings of spontaneous rhythmic bursts in swimmeret motor neurons recorded from RS and PS nerves. $\mathrm{PSE}=$ Power-stroke excitor; RSE $=$ return-stroke excitor; PSI = power-stroke inhibitor; RSI = return-stroke inhibitor. Modified from Mulloney [166] and Mulloney et al. [196]. f Schematic of metachronal rhythm in a chain of abdominal ganglia. PSE = Powerstroke excitor. $\mathbf{g}$ The swimmeret CPG circuit. Data from Mulloney [166], Jones et al. [177] and Skinner and Mulloney [197]. DSC = Descending coordinating interneuron; ASC $=$ ascending coordinating interneuron; $\mathrm{PSE}=$ power-stroke excitor; RSI = power-stroke inhibitor.

Crustacean Motor Pattern Generator

Networks ical stimulation of the heart wall affects the cardiac rhythm on a cycle-by-cycle basis [138]. Intracellular recordings from large cells show that spontaneous heart contractions, or stretch-induced increases in heart muscle tension, hyperpolarize the neurons and induce a rebound burst in the neurons after the stretch (fig. 4b). Depolarization latency decreases with increased stretch amplitude and duration, and repetitive mechanical stimulation entrains the network. The cardiac neurons may thus be part of a one-neuron reflex feedback loop in which the contraction caused by one cardiac burst helps induce the neuron depolarization responsible for the rhythm's next burst.

Contrary to this explanation, however, is the observation that isolated cardiac ganglia are rhythmic. This rhythmicity is due to slowly depolarizing pacemaker currents in the small cells that eventually trigger them to burst (see below). A possible reconciliation of these conflicting data is that dissection of the cardiac ganglion from the heart results in an injury current which is the (nonphysiological) basis of the small cell pacemaker currents. Large cells maintained in cell culture produce spontaneous driver potentials [139], but these are not seen in intact networks, and thus may result from changes in large cell membrane conductances induced by long-term synaptic isolation and cell culture conditions.

Active Neuron Properties Underlie the in vitro Rhythm

Much of this work has been done with isolated cardiac ganglia. Under these conditions, cardiac CPG rhythmicity may arise in part from a nonphysiological 'leak' current in the small cells. Nonetheless, if interpreted in light of most recent results, the isolated ganglion data are valuable for understanding cardiac rhythmogenesis. The in vitro rhythm results from active, plateau-like properties termed driver potentials (fig. 4c). In the in vitro preparation, the small cells spontaneously slowly depolarize (presumably from the injury current noted above), and eventually reach the driver potential threshold, which induces a spike burst. These spikes excite the large cells, which are then driven over the driver potential threshold and produce a spike burst as well. Large-cell synchrony is assured by the electrical coupling among the neurons.

Large-cell driver potentials have been most studied because the potentials in these neurons arise at a site electrically distant from the spike initiation zone, and driver potential currents are thus easily separable from action potential currents. The driver potential threshold and amplitude are proportional to the stimulation rate increasing the time between depolarizing inputs decreases the activation threshold and increases the potential am- 
plitude - but depolarization of isolated (ligatured or TTX treated) large cells above $-45 \mathrm{mV}$ generally triggers a driver potential. Physiological cardiac cycle periods are approximately $1 \mathrm{~s}$, but lowest activation thresholds and maximum driver potential amplitudes occur with an interstimulation interval of $\geq 10 \mathrm{~s}$. The driver potentials primarily depend on a voltage-dependent $\mathrm{Ca}^{2+}$ current, but three potassium currents (fast $I_{a}$, slowly inactivating $\mathrm{I}_{\mathrm{k}}$, and the calcium-dependent $\mathrm{I}_{\mathrm{KCa}}$ ), a noninactivating sodium current, and $\mathrm{I}_{\mathrm{h}}$, a hyperpolarizing activated outward current, are also present in cardiac ganglion neurons [140-144].

Combining these data and the proprioceptive driving data gives the following hypothesis for cardiac rhythmicity in vivo (fig. $4 \mathrm{~d}$ ). The tension induced by the previous heartbeat hyperpolarizes the large and small cells due to mechanosensitive conductances in their dendrites. This hyperpolarization induces postinhibitory rebound in the neurons, and this, possibly in combination with a smallcell depolarizing pacemaker current, results in the small cells depolarizing above driver potential threshold and firing a burst. The postinhibitory rebound also induces a driver potential in the large cells, and these driver potentials passively conduct toward the distant spike initiation zones of the large cells. The combined small-cell excitatory input and the decremented large-cell driver potentials drive the large-cell spike initiation zones above threshold. Large-cell spikes induce another heart contraction, and the cycle repeats.

\section{Higher-Order Control of the Cardiac Rhythm}

Three extrinsic neurons, two excitors and one inhibitor, control the cardiac rhythm [145]. The inhibitor produces discrete inhibitory postsynaptic potentials, and the excitors a slow depolarization, in the large cells. One excitor contains tyrosine hydroxylase [137], implying the presence of dopamine, and dopamine accelerates the heart rhythm. A candidate transmitter for the remaining excitor is acetylcholine, which also excites the heart [146]. The pericardial organs, which contain 5-HT, dopamine, and octopamine and the peptides proctolin, CCAP, and FMRFamide-like peptides, all of which change heart rate and increase spike frequency, burst spike number, and burst duration [147-155], may be a source of neurohemal modulation for the heart.

\section{Swimmeret System}

\section{Overview}

Swimmerets are paired appendages ( 2 per segment) located on the ventral side of 4 adjacent abdominal segments. Swimmeret beating aids forward swimming, burrow ventilation, egg ventilation in gravid females, and postural control. The swimmerets of each segment beat in phase; power and return motor neurons fire in strict antiphase (fig. 4e). Swimmerets in adjacent segments beat with a fixed anterior-posterior phase relationship that results in a posterior to anterior metachronal wave of beating along the body axis (fig. 4f) [156]. The swimmeret system was the first example of both a centrally generated motor pattern [10,156-158] and of 'command' neurons neurons that start and stop CPG rhythmicity [159]. The system has more recently served as an experimental and computational model for investigating coupled oscillator networks (phase-locked CPGs that coordinate the activity of multiple body segments).

\section{Cellular Basis of Pattern Generation within a Single Segment}

If the intersegmental connectives are cut, each ganglion generates an independent swimmeret rhythm in which the 2 swimmerets of each segment still beat in phase. When the ganglion is bisected along the midline, the 2 swimmerets continue to beat, but their activity is no longer coordinated. The swimmeret rhythm is thus generated by chains of serially repeated pairs of CPGs, one in each hemiganglion, that are interconnected both bilaterally across the midline and across body segments.

Current injection into swimmeret motor neurons resets the rhythm, and it was originally proposed that the motor neurons were an important part of the CPG [160]. It has since been shown that the synaptic connections among the motor neurons, and from them to the CPGis, are weak and that the motor neurons are not required for normal CPG activity [161]. The actual CPG is composed of interneurons. Eight interneurons that alter motor neuron activity are present in each hemiganglion. Current injection into 4 of these can reset the rhythm (which are thus presumably members of the CPG). The synaptic interconnections of the CPG neurons have not been experimentally determined by paired neuron recordings, but the hypothetical model shown in figure $4 \mathrm{~g}$ (dashed box) is consistent with observed interneuron activity. Current injection into the other 4 interneurons changes motor neuron firing strength, but cannot reset the rhythm. Two of these neurons oscillate with the CPG (the activity 
of the others is unknown). None of the interneurons are spiking, and thus the entire 8-neuron ensemble functions via graded synaptic transmission alone.

Swimmeret motor neurons use GABA $[162,163]$ and glutamate $[164,165]$ as transmitters, and are inhibited by GABA and glutamate [161]. All CPGi to motor neuron connections are inhibitory, and it is therefore tempting to speculate that the CPGis use GABA or glutamate as transmitters. However, picrotoxin (which blocks GABAergic synapses in this system) does not abolish CPG rhythmicity [161]. The basis of motor neuron firing is unknown. Two possibilities [166] are tonic excitatory drive to the motor neurons (from unknown sources) which inhibitory input from the CPG transforms into bursts and motor neuron endogenous properties (e.g. postinhibitory rebound and plateau potentials), as is seen in the stomatogastric, ventilatory, and cardiac ganglion systems.

With respect to intrasegmental coordination of the 2 swimmerets, there are 5 bilaterally projecting interneurons in each ganglion, 2 of which are spiking [167]. Interneurons $1 \mathrm{~A}$ and $1 \mathrm{~B}$ receive discrete, presumably actionpotential-induced, postsynaptic potentials in phase with the coupled CPG activity, and TTX (which blocks action potential production) uncouples the activity of the 2 swimmerets [168]. These data suggest that at least 1 of the bilaterally projecting spiking interneurons coordinates the 2 swimmeret CPGs of each segment.

\section{Intersegmental Coordination}

Three bilaterally symmetrical, segmentally repeated interneurons mediate intersegmental coordination [169, 170]. Recordings from coordinating axons in the interganglionic connectives, and experiments in which coupling was maintained between nonneighboring ganglia when synaptic transmission in single intervening ganglia was blocked with low $\mathrm{Ca}^{2+} /$ high $\mathrm{Mg}^{2+}$ saline, show that the intersegmental coordinating interneurons extend at least 2 ganglia from their ganglion of origin [171, 172]. TTX abolishes intersegmental coordination, which thus depends on action potentials. CPGi oscillations are also more variable in TTX, suggesting that intersegmental or bilateral (since 2 of the unisegmental bilateral interneurons are also spiking) connections refine or stabilize the motor pattern via spike-mediated timing signals.

Metachronal phase coupling is maintained in two ganglia chains [173]. The synaptic connectivity from the CPGis (and/or motor neurons) onto the intersegmental coordinating interneurons, and from the intersegmental coordinating interneurons onto CPGis (and/or motor neurons), have not been experimentally determined. The- oretical work with coupled oscillator chains suggests that one way a metachronal wave can arise is if there is an anterior to posterior increase in the inherent cycle periods of the individual oscillators of the chain. However, the cycle period of isolated segment CPGs does not increase from anterior to posterior segments, nor does altering anterior ganglion $\mathrm{CPG}$ cycle period alter the metachronal wave $[174,175]$. This mechanism is thus unlikely to underlie the observed intersegmental coordination. An alternative mechanism is based on the observation that ascending intersegmental coordination interneurons fire in phase with interneuron $2 \mathrm{~A}$, and descending intersegmental coordination interneurons with interneuron 1B. Comparison of modeling and experimental data [176, 177] suggests that patterns in figure $4 \mathrm{~g}$, in which ascending interneurons inhibit interneuron $1 \mathrm{~A}$ and excite interneuron $1 \mathrm{~B}$, and descending interneurons inhibit interneuron $1 \mathrm{~A}$ and either inhibit interneuron $2 \mathrm{~A}$ or excite interneuron $1 \mathrm{~B}$, best fit the data.

\section{Extrinsic Control of the Swimmeret System}

Descending interneurons can start the swimmeret rhythm and alter its frequency [108, 159, 178, 179]. Immunohistochemical work and comparison of interneuron stimulation and modulator application shows that these inputs use at least proctolin (excitation) and octopamine (inhibition) [180-183]. Serotonin [182], dopamine [184], the cholinergic agonists pilocarpine and nicotine [185], and the peptide CCAP also modulate swimmeret activity; CCAP-like immunoreactivity is present in the region of the abdominal ganglia where the CPGis are located [186].

\section{Proprioceptive Feedback}

Cuticular receptors, strain-sensitive hypodermal mechanoreceptors, setae, and hairs are present on the abdomen and respond to swimmeret and water movements [187-190]. Feedback from these sources is not required for individual CPG activity or bilateral and intersegmental coordination, but maintaining these feedback loops amplifies and reinforces system activity [187], and some [191], but not all [192], can entrain the rhythm. The feedback is rapid enough that cycle-by-cycle modification of the rhythm is possible [188]. Proprioceptive feedback may also play a role in maintaining intersegmental coordination [193]. As in the ventilatory system, several sensory neurons are nonspiking [191, 192] and receive cyclic input in phase with central activity that may serve to modulate or gate sensory feedback. 


\section{References}

1 Basar E, Bullock T: Induced Rhythms in the Brain. Boston, Birkhäuser, 1992.

2 Bevan MD, Magill PJ, Terman D, Bolam JP, Wilson CJ: Move to the rhythm: Oscillations in the subthalamic nucleus-external globus pallidus network. Trends Neurosci 2002;25:525531 .

3 Chrobak JJ, Buzsaki G: High-frequency oscillations in the output networks of the hippocampal-entorhinal axis of the freely behaving rat. $\mathrm{J}$ Neurosci 1996;16:3056-3066.

4 Freeman W: Nonlinear neural dynamics in olfaction as a model for cognition; in Basar $\mathrm{E}$ (ed): Dynamics of Sensory and Cognitive Processing by the Brain. Berlin, Springer, 1988, pp 102-121.

5 Gray CM: Synchronous oscillations in neuronal systems: Mechanisms and functions. J Comput Neurosci 1995;1:11-38.

6 Kocsis B, Bragin A, Buzsaki G: Interdependence of multiple theta generators in the hippocampus: A partial coherence analysis. J Neurosci 1999; 19:6200-6212.

7 Leznik E, Makarenko V, Llinas R: Electrotonically mediated oscillatory patterns in neuronal ensembles: An in vitro voltage-dependent dyeimaging study in the inferior olive. J Neurosci 2002;22:2804-2815.

8 Steriade M, Contreras D, Amzica F, Timofeey I: Synchronization of fast $(30-40 \mathrm{~Hz})$ spontaneous oscillations in intrathalamic and thalamocortical networks. J Neurosci 1996;16: 2788-2808.

9 Swinnen SP: Intermanual coordination: From behavioural principles to neural-network interactions. Nat Rev Neurosci 2002;3:348-359.

10 Hughes GM, Wiersma CAG: The co-ordination of swimmeret movement in the crayfish, Procambarus clarkii (Girard). J Exp Biol 1960; 39:657-670.

11 Wilson D: The central nervous control of locust flight. J Exp Biol 1961;38:471-490.

12 Delcomyn F: Neural basis of rhythmic behavior in animals. Science 1980;210:492-498.

13 Duysens J, Clarac F, Cruse H: Load-regulating mechanisms in gait and posture: Comparative aspects. Physiol Rev 2000;80:83-133.

14 Büschges A, El Manira A: Sensory pathways and their modulation in the control of locomotion. Curr Opin Neurobiol 1998;8:733-739.

15 Clarac F, Cattaert D: Invertebrate presynaptic inhibition and motor control. Exp Brain Res 1996;112:163-180.

16 Clarac F, Cattaert D, Le Ray D: Central control components of a 'simple' stretch reflex. Trends Neurosci 2000;23:199-208.

17 Selverston AI, Russell DF, Miller JP, King DG: The stomatogastric nervous system: Structure and function of a small neural network. Prog Neurobiol 1976;7:215-290.

18 Eisen JS, Marder E: Mechanisms underlying pattern generation in lobster stomatogastric ganglion as determined by selective inactivation of identified neurons. 3. Synaptic connections of electrically coupled pyloric neurons. J Neurophysiol 1982;48:1392-1415.
19 Johnson BR, Peck JH, Harris-Warrick RM: Dopamine induces sign reversal at mixed chemical-electrical synapses. Brain Res 1993; 625:159-164.

20 Miller JP, Selverston AI: Mechanisms underlying pattern generation in lobster stomatogastric ganglion as determined by selective inactivation of identified neurons. 4. Network properties of pyloric system. J Neurophysiol 1982;48: 1416-1432.

21 Miller JP, Selverston AI: Mechanisms underlying pattern generation in lobster stomatogastric ganglion as determined by selective inactivation of identified neurons. 2. Oscillatory properties of pyloric neurons. J Neurophysiol 1982; 48:1378-1391.

22 Selverston AI, Miller JP: Mechanisms underlying pattern generation in lobster stomatogastric ganglion as determined by selective inactivation of identified neurons. 1. Pyloric system. J Neurophysiol 1980;44:1102-1121.

23 Mulloney B: Organization of the stomatogastric ganglion of the spiny lobster. 5. Coordination of the gastric and pyloric systems. J Comp Physiol 1977;122:227-240.

24 Mulloney B, Selverston AI: Organization of the stomatogastric ganglion in the spiny lobster. 1. Neurons driving the lateral teeth. J Comp Physiol 1974;91:1-32.

25 Mulloney B, Selverston AI: Organization of the stomatogastric system in the spiny lobster. 3 . Coordination of the two subsets of the gastric system. J Comp Physiol 1974;91:53-78.

26 Selverston AI, Mulloney B: Organization of the stomatogastric ganglion of spiny lobster. 2 . Neurons driving the medial tooth. J Comp Physiol 1974;91:33-51.

27 Russell DF, Hartline DK: A multiaction synapse evoking both EPSPs and enhancement of endogenous bursting. Brain Res 1981;223:1938.

28 Claiborne BJ, Selverston AI: Histamine as a neurotransmitter in the stomatogastric nervous system of the spiny lobster. J Neurosci 1984;4: 708-721.

29 Claiborne BJ, Selverston AI: Localization of stomatogastric IV neuron cell bodies in lobster brain. J Comp Physiol A 1984;154:27-32.

30 Sigvardt KA, Mulloney B: Properties of synapses made by IVN command-interneurones in the stomatogastric ganglion of the spiny lobster Panulirus interruptus. J Exp Biol 1982;97:153168.

31 Thuma JB, Hooper SL: Quantification of cardiac sac network effects on a movement-related parameter of pyloric network output in the lobster. J Neurophysiol 2003;89:745-753.

32 Thuma JB, Hooper SL: Quantification of gastric mill network effects on a movement related parameter of pyloric network output in the lobster. J Neurophysiol 2002;87:2372-2384.

33 Morris LG, Thuma JB, Hooper SL: Muscles express motor patterns of non-innervating neural networks by filtering broad-band input. Nat Neurosci 2000;3:245-250.
34 Thuma J, Morris L, Weaver A, Hooper S: Lobster (Panulirus interruptus) pyloric muscles express the motor patterns of three neural networks, only one of which innervates the muscles. J Neurosci 2003;23:8911-8920.

35 Nadim F, Manor Y, Nusbaum MP, Marder E Frequency regulation of a slow rhythm by a fast periodic input. J Neurosci 1998;18:50535067.

36 Bartos M, Manor Y, Nadim F, Marder E, Nusbaum MP: Coordination of fast and slow rhythmic neuronal circuits. J Neurosci 1999;19: 6650-6660.

37 Ayali A, Harris-Warrick RM: Interaction of dopamine and cardiac sac modulatory inputs on the pyloric network in the lobster stomatogastric ganglion. Brain Res 1998;794:155-161.

38 Ayali A, Harris-Warrick RM: Monoamine control of the pacemaker kernel and cycle frequency in the lobster pyloric network. J Neurosci 1999;19:6712-6722.

39 Beltz B, Eisen JS, Flamm R, Harris-Warrick RM, Hooper SL, Marder E: Serotonergic innervation and modulation of the stomatogastric ganglion of three decapod crustaceans (Panulirus interruptus, Homarus americanus and Cancer irroratus). J Exp Biol 1984;109:35-54.

40 Dickinson PS, Hauptman J, Hetling J, Mahadevan A: RCPH modulation of a multi-oscillator network: Effects on the pyloric network of the spiny lobster. J Neurophysiol 2001;85: 1424-1435.

41 Flamm RE, Harris-Warrick RM: Aminergic modulation in lobster stomatogastric ganglion. 1. Effects on motor pattern and activity of neurons within the pyloric circuit. J Neurophysiol 1986;55:847-865.

42 Harris-Warrick RM, Marder E: Modulation of neural networks for behavior. Annu Rev Neurosci 1991;14:39-57.

43 Hooper SL, Marder E: Modulation of a central pattern generator by two neuropeptides, proctolin and FMRFamide. Brain Res 1984;305: 186-191.

44 Hooper SL, Marder E: Modulation of the lobster pyloric rhythm by the peptide proctolin. J Neurosci 1987;7:2097-2112.

45 Katz PS, Harris-Warrick RM: Actions of identified neuromodulatory neurons in a simple motor system. Trends Neurosci 1990;13:367373.

46 Katz PS, Harris-Warrick RM: Neuromodulation of the crab pyloric central pattern generator by serotonergic/cholinergic proprioceptive afferents. J Neurosci 1990;10:1495-1512.

47 Nagy F, Dickinson PS: Control of a central pattern generator by an identified modulatory interneurone in crustacea. 1. Modulation of the pyloric motor output. J Exp Biol 1983;105:3358.

48 Nusbaum MP, Marder E: A neuronal role for a crustacean red pigment concentrating hormone-like peptide - Neuromodulation of the pyloric rhythm in the crab, Cancer borealis. $\mathrm{J}$ Exp Biol 1988;135:165-181. 
49 Nusbaum MP, Marder E: A modulatory proctolin-containing neuron (MPN). 2. State-dependent modulation of rhythmic motor activity. J Neurosci 1989;9:1600-1607.

50 Turrigiano GG, Selverston AI: Cholecystokinin-like peptide is a modulator of a crustacean central pattern generator. J Neurosci 1989;9: 2486-2501.

51 Turrigiano GG, Selverston AI: A cholecystokinin-like hormone activates a feeding-related neural circuit in lobster. Nature 1990;344:866868.

52 Weimann JM, Marder E, Evans B, Calabrese RL: The effects of SDRNFLRFamide and TNRNFLRFamide on the motor patterns of the stomatogastric ganglion of the crab Cancer borealis. J Exp Biol 1993;181:1-26.

53 Blitz DM, Christie AE, Marder E, Nusbaum MP: Distribution and effects of tachykinin-like peptides in the stomatogastric nervous system of the crab, Cancer borealis. J Comp Neurol 1995;354:282-294.

54 Blitz DM, Christie AE, Coleman MJ, Norris BJ, Marder E, Nusbaum MP: Different proctolin neurons elicit distinct motor patterns from a multifunctional neuronal network. J Neurosci 1999;19:5449-5463.

55 Hooper SL, Moulins M: Switching of a neuron from one network to another by sensory-induced changes in membrane properties. Science 1989;244:1587-1589.

56 Hooper SL, Moulins M: Cellular and synaptic mechanisms responsible for a long-lasting restructuring of the lobster pyloric network. J Neurophysiol 1990;64:1574-1589.

57 Hooper SL, Moulins M, Nonnotte L: Sensory input induces long-lasting changes in the output of the lobster pyloric network. J Neurophysiol 1990;64:1555-1573.

58 Weimann JM, Marder E: Switching neurons are integral members of multiple oscillatory networks. Curr Biol 1994;4:896-902.

59 Weimann JM, Meyrand P, Marder E: Neurons that form multiple pattern generators: Identification and multiple activity patterns of gastric/ pyloric neurons in the crab stomatogastric system. J Neurophysiol 1991;65:111-122.

60 Katz PS, Harris-Warrick RM: Recruitment of crab gastric mill neurons into the pyloric motor pattern by mechanosensory afferent stimulation. J Neurophysiol 1991;65:1442-1451.

61 Dickinson PS, Mecsas C, Marder E: Neuropeptide fusion of two motor-pattern generator circuits. Nature 1990;344:155-158.

62 Meyrand P, Simmers J, Moulins M: Construction of a pattern-generating circuit with neurons of different networks. Nature 1991;351: 60-63.

63 Meyrand P, Simmers J, Moulins M: Dynamic construction of a neural network from multiple pattern generators in the lobster stomatogastric nervous system. J Neurosci 1994;14:630-644.

64 Hooper SL: Phase maintenance in the pyloric pattern of the lobster (Panulirus interruptus) stomatogastric ganglion. J Comput Neurosci 1997:4:191-205.
65 Anderson WW, Barker DL: Synaptic mechanisms that generate network oscillations in the absence of discrete postsynaptic potentials. J Exp Zool 1981;216:187-191.

66 Raper JA: Nonimpulse-mediated synaptic transmission during the generation of a cyclic motor program. Science 1979;205:304-306.

67 Graubard K: Synaptic transmission without action potentials: Input-output properties of a nonspiking presynaptic neuron. J Neurophysiol 1978;41:1014-1025.

68 Graubard K, Raper JA, Hartline DK: Graded synaptic transmission between spiking neurons. Proc Natl Acad Sci USA 1980;77:37333735.

69 Graubard K, Raper JA, Hartline DK: Graded synaptic transmission between identified spiking neurons. J Neurophysiol 1983;50:508521.

70 Bal T, Nagy F, Moulins M: The pyloric central pattern generator in crustacea: A set of conditional neuronal oscillators. J Comp Physiol 1988; 163:715-727.

71 Russell DF, Hartline DK: Bursting neural networks: A reexamination. Science 1978;200: 453-456.

72 Russell DF, Hartline DK: Slow active potentials and bursting motor patterns in pyloric network of the lobster, Panulirus interruptus. J Neurophysiol 1982;48:914-937.

73 Hartline DK, Gassie DV Jr: Pattern generation in the lobster (Panulirus) stomatogastric ganglion. 1. Pyloric neuron kinetics and synaptic interactions. Biol Cybern 1979;33:209-222.

74 Perkel DH, Mulloney B: Motor pattern production in reciprocally inhibitory neurons exhibiting postinhibitory rebound. Science 1974; 185:181-183.

75 Weaver A, Hooper S: Relating network synaptic connectivity and network activity in the lobster (Panulirus interruptus) pyloric network. J Neurophysiol 2003;90:2378-2386.

76 Bartos M, Nusbaum MP: Intercircuit control of motor pattern modulation by presynaptic inhibition. J Neurosci 1997; 17:2247-2256.

77 Coleman MJ, Meyrand P, Nusbaum MP: A switch between two modes of synaptic transmission mediated by presynaptic inhibition. Nature 1995;378:502-505.

78 Coleman MJ, Nusbaum MP: Functional consequences of compartmentalization of synaptic input. J Neurosci 1994;14:6544-6552.

79 Nusbaum MP: Presynaptic control of neurones in pattern-generating networks. Curr Opin Neurobiol 1994;4:909-914.

80 Hooper SL: Transduction of temporal patterns by single neurons. Nat Neurosci 1998;1:720726.

81 Nadim F, Manor Y: The role of short-term synaptic dynamics in motor control. Curr Opin Neurobiol 2000; 10:683-690.

82 Nadim F, Manor Y, Bose A: Control of network output by synaptic depression. Neurocomputing 2001;38-40:781-787.

83 Nadim F, Manor Y, Kopell N, Marder E: Synaptic depression creates a switch that controls the frequency of an oscillatory circuit. Proc Natl Acad Sci USA 1999;96:8206-8211.
84 Dando MR, Maynard DM: The sensory innervation of the foregut of Panulirus argus (Decapoda crustacea). Mar Behav Physiol 1974;2: 283-305.

85 Sigvardt KA, Mulloney B: Sensory alteration of motor patterns in the stomatogastric nervous system of the spiny lobster Panulirus interruptus. J Exp Biol 1982;97:137-152.

86 Katz PS, Eigg MH, Harris-Warrick RM: Serotonergic/cholinergic muscle receptor cells in the crab stomatogastric nervous system. 1. Identification and characterization of the gastropyloric receptor cells. J Neurophysiol 1989; 62:558-570.

87 Katz PS, Harris-Warrick RM: Serotonergic/ cholinergic muscle receptor cells in the crab stomatogastric nervous system. 2. Rapid nicotinic and prolonged modulatory effects on neurons in the stomatogastric ganglion. J Neurophysiol 1989;62:571-581.

88 Morris LG, Hooper SL: Muscle response to changing neuronal input in the lobster (Panulirus interruptus) stomatogastric system: Slow muscle properties can transform rhythmic input into tonic output. J Neurosci 1998; 18: 3433-3442.

89 Young RE: Neuromuscular control of ventilation in the crab Carcinus maenas. J Comp Physiol 1975;101:1-37.

90 Wilkens JL, Young RE: Patterns and bilateral coordination of scaphognathite rhythms in the lobster Homarus americanus. J Exp Biol 1975; 63:219-235.

91 Mendelson M: Oscillator neurons in crustacean ganglia. Science 1971;171:1170-1173.

92 Simmers AJ, Bush BMH: Non-spiking neurones controlling ventilation in crabs. Brain Res 1980;197:247-252.

93 DiCaprio RA: Nonspiking interneurons in the ventilatory central pattern generator of the shore crab, Carcinus maenas. J Comp Neurol 1989;285:83-106.

94 Wilkens JL, Wilkens LA, McMahon BR: Central control of cardiac and scaphognathite pacemakers in the crab, Cancer magister. J Comp Physiol 1974;90:89-104.

95 DiCaprio RA, Fourtner CR: Neural control of ventilation in the shore crab, Carcinus maenas. 2. Frequency-modulating interneurons. J Comp Physiol 1988;162:375-388.

96 Burrows M, Siegler MVS: Graded synaptic transmission between local interneurones and motor neurones in the metathoracic ganglion of the locust. J Physiol 1978;285:231-255.

97 Simmers AJ, Bush BMH: Central nervous mechanisms controlling rhythmic burst generation in the ventilatory motoneurons of Carcinus maenas. J Comp Physiol 1983;150:1-21.

98 DiCaprio RA, Fourtner CR: Neural control of ventilation in the shore crab, Carcinus maenas. 1. Scaphognathite motor neurons and their effect on the ventilatory rhythm. J Comp Physiol 1984;155:397-406.

99 DiCaprio RA: Plateau potentials in motor neurons in the ventilatory system of the crab. J Exp Biol 1997;200:1725-1736. 
100 Dickinson PS, Nagy F: Control of a central pattern generator by an identified modulatory interneurone in crustacea. 2 . Induction and modification of plateau properties in pyloric neurones. J Exp Biol 1983;105:59-82.

101 Kiehn O, Harris-Warrick RM: Serotonergic stretch receptors induce plateau properties in a crustacean motor neuron by a dual-conductance mechanism. J Neurophysiol 1992;68: 485-495.

102 Ramirez J-M, Pearson KG: Octopamine induces bursting and plateau potentials in insect neurones. Brain Res 1991;549:332-337.

103 Conway BA, Hultborn H, Kiehn O, Mintz I: Plateau potentials in 1-motoneurones induced by intravenous injection of $L$-dopa and clonodine in the spinal cat. J Physiol 1988; 405:369-384.

104 Hounsgaard J, Hultborn H, Jespersen B, Kiehn O: Bistability of O-motoneurons in the decerebrate cat and in the acute spinal cat after intravenous 5-hydroxytryptophan. J Physiol 1988;405:345-367.

105 Hounsgaard J, Kiehn O: Serotonin-induced bistability of turtle motoneurones caused by a nifedipine-sensitive calcium plateau potential. J Physiol 1989;414:265-282.

106 Grillner S: Control of locomotion in bipeds, tetrapods and fish; in Brooks VB (ed): Handbook of Physiology. Maryland, Waverly Press, 1981, vol 2, pp 1179-1236.

107 Pearson KG, Iles JF: Discharge patterns of coxal levator and depressor motoneurones of the cockroach, Periplaneta americana. J Exp Biol 1970;52:139-165.

108 Davis WJ: The neural control of swimmeret beating in the lobster. J Exp Biol 1969;50:99117.

109 Paul DH: Swimming behavior of the sand crab, Emerita analoga (Crustacea, Anomura). 1. Analysis of the uropod stroke. Z Vergl Physiol 1971;75:233-258.

110 Hume RI, Getting PA, Del Beccaro MA: Motor organization of Tritonia diomedea swimming. 1. Quantitative analysis of swim behavior and flexion neuron firing patterns. J Neurophysiol 1982;47:60-74.

111 Williams TL: Phase coupling by synaptic spread in chains of coupled neuronal oscillators. Science 1992;258:662-665.

112 Friesen WO, Pearce RA: Mechanisms of intersegmental coordination in leech locomotion. Semin Neurosci 1993;5:41-47.

113 Wilkens JL: Neuronal control of respiration in decapod crustacea. Fed Proc 1976;35: 2000-2006.

114 Mercier AJ, Wilkens JL: Analysis of the scaphognathite ventilatory pump in the shore crab Carcinus maenas. 3. Neuromuscular mechanisms. J Exp Biol 1984;1 13:83-99.

115 DiCaprio RA, Jordan G, Hampton T: Maintenance of motor pattern phase relationships in the ventilatory system of the crab. J Exp Biol 1997;200:963-974.
116 Hughes GM, Knights B, Scammell C: The distribution of partial pressure of oxygen and hydrostatic pressure changes within the branchial chambers in relation to gill ventilation of the shore crab Carcinus maenas L. J Exp Biol 1969;51:203-220.

117 Mercier AJ, Wilkens JL: Analysis of the scaphognathite ventilatory pump in the shore crab Carcinus maenas. 1. Work and power. J Exp Biol 1984;113:55-68.

118 Wilkens JL, Wilkes PRH, Evans J: Analysis of the scaphognathite ventilatory pump in the shore crab Carcinus maenas. 2. Pumping efficiency and metabolic cost. J Exp Biol 1984; 113:69-81.

119 Simmers AJ, Bush BMH: Motor program switching in the ventilatory system of Carcinus maenas: The neuronal basis of bimodal scaphognathite beating. J Exp Biol 1983;104: 163-182.

120 DiCaprio RA: An interneurone mediating motor programme switching in the ventilatory system of the crab. J Exp Biol 1990;154: 517-535.

121 Cumberlidge N, Uglow RF: Heart and scaphognathite activity in the shore crab Carcinus maenas (L). J Exp Mar Biol Ecol 1977; 28:87-107.

122 Taylor EW: Control and coordination of ventilation and circulation in crustaceans - Responses to hypoxia and exercise. J Exp Biol 1987;100:289-319.

123 Pasztor VM: The neurophysiology of respiration in decapod crustacea. 2 . The sensory system. Can J Zool 1969;47:435-441.

124 Pasztor VM, Bush BMH: Impulse coded and analog signaling in single mechanoreceptor neurons. Science 1982;215:1635-1637.

125 DiCaprio RA: Gating of afferent input by a central pattern generator. J Neurophysiol 1999;81:950-953.

126 Rudomin P, Quevedo J, Eguibar JR: Presynaptic modulation of spinal reflexes. Curr Opin Neurobiol 1993;3:997-1004.

127 El Manira A, DiCaprio RA, Cattaert D, Clarac $\mathrm{F}$ : Monosynaptic interjoint reflexes and their central modulation during fictive locomotion in crayfish. Eur J Neurosci 1991;3: 1219-1231.

128 Sillar KT, Skorupski P: Central input to primary afferent neurons in crayfish, Pacifastacus leniusculus, is correlated with rhythmic motor output of thoracic ganglia. J Neurophysiol 1986;55:678-688.

129 Paul DH: Nonspiking stretch receptors of the crayfish swimmeret receive an efference copy of the central motor pattern for the swimmeret. J Exp Biol 1989;141:257-264.

130 Maynard DM: Activity in a crustacean ganglion. 2. Pattern and interaction in burst formation. Biol Bull 1955;109:156-170.

131 Hartline DK: Impulse identification and axon mapping of the nine neurons in the cardiac ganglion of the lobster, Homarus americanus. J Exp Biol 1967;47:327-340.
132 Delgado J, Oyola E, Miller MW: Localization of GABA- and glutamate-like immunoreactivity in the cardiac ganglion of the lobster, Panulirus argus. J Neurocytol 2001;29:605619

133 Mirolli M, Cooke IM, Talbott SR, Miller MW: Structure and localization of synaptic complexes in the cardiac ganglion of a portunid crab. J Neurocytol 1987;16:115-130.

134 Watanabe A: The interaction of electrical activity among neurons of lobster cardiac ganglia. Jpn J Physiol 1958;8:305-318.

135 Tazaki K, Cooke IM: Spontaneous electrical activity and interaction of large and small cells in the cardiac ganglion of the crab, Portunus sanguinolentus. J Neurophysiol 1979;42: 975-999.

136 Scholz NL, Labenia J, De Vente J, Graubard K, Goy MF: Expression of nitric oxide synthase and nitric oxide-sensitive guanylate cyclase in the crustacean cardiac ganglion. $\mathrm{J}$ Comp Neurol 2002;454:158-167.

137 Cooke IM: Reliable, responsive pacemaking and pattern generation with minimal cell numbers: The crustacean cardiac ganglion. Biol Bull 2002;202:108-136.

138 Sakurai A, Wilkens JL: Tension sensitivity of the heart pacemaker neurons in the isopod crustacean Ligia pallasii. J Exp Biol 2003; 206:105-115.

139 Saver MA, Wilkens JL, Syed NI: In situ and in vitro identification and characterization of cardiac ganglion neurons in the crab, Carcinus maenas. J Neurophysiol 1999;81:29642976.

140 Tazaki K, Cooke I: Neural mechanisms underlying rhythmic bursts in crustacean cardiac ganglia. Symp Soc Exp Biol 1983;37: 129-157.

141 Tazaki K, Cooke IM: Ionic bases of slow, depolarizing responses of cardiac ganglion neurons in the crab, Portunus sanguinolentus. J Neurophysiol 1979;42:1022-1047.

142 Tazaki K, Cooke IM: Isolation and characterization of slow, depolarizing responses of cardiac ganglion neurons in the crab, Portunus sanguinolentus. J Neurophysiol 1979;42: 1000-1021.

143 Tazaki K, Cooke IM: Characterization of Ca current underlying burst formation in lobster cardiac ganglion motorneurons. J Neurophysiol 1990;63:370-383.

144 Tazaki K, Cooke IM: Currents under voltage clamp of burst-forming neurons of the cardiac ganglion of the lobster (Homarus americanus). J Neurophysiol 1986;56:1739-1762.

145 Alexandrowicz JS: The innervation of the heart of the crustacea. 1. Decapoda. Q J Micro Sci 1932;75:182-249.

146 Sullivan RE, Miller MW: Cholinergic activation of the lobster cardiac ganglion. J Neurobiol 1990;21:639-650.

147 Kuramoto T, Yamagishi H: Physiological anatomy, burst formation and burst frequency of the cardiac ganglion of crustaceans. Physiol Zool 1990;63:102-116. 
148 Cooke IM, Hartline DK: Neurohormonal alteration of integrative properties of the cardiac ganglion of the lobster Homarus americanus. J Exp Biol 1975;63:33-52.

149 Benson JA: Octopamine alters rhythmic activity in the isolated cardiac ganglion of the crab, Portunus sanguinolentus. Neurosci Lett 1984;44:59-64.

150 Saver MA, Wilkens JL: Comparison of the effects of five hormones on intact and open heart cardiac ganglionic output and myocardial contractility in the shore crab Carcinus maenas. Comp Biochem Physiol A 1998;120: 301-310.

151 Sullivan RE, Friend BJ, Barker DL: Structure and function of spiny lobster ligamental nerve plexuses: Evidence for synthesis storage and secretion of biogenic amines. J Neurobiol 1977;8:581-606.

152 Berlind A: Monoamine pharmacology of the lobster cardiac ganglion. Comp Biochem Physiol C Toxicol Pharmacol 2001;128:377390.

153 Berlind A: Dopamine and 5-hydroxytryptamine actions on the cardiac ganglion of the lobster Homarus americanus. J Comp Physiol 1998;182:363-376.

154 Sullivan RE, Miller MW: Dual effects of proctolin on the rhythmic burst activity of the cardiac ganglion. J Neurobiol 1984;15:173-196.

155 Mercier AJ, Russenes RT: Modulation of crayfish hearts by FMRFamide-related peptides. Biol Bull 1992;182:333-340.

156 Ikeda K, Wiersma CAG: Autogenic rhythmicity in the abdominal ganglia of the crayfish: The control of swimmeret movements. Comp Biochem Physiol A 1964;12:107-115.

157 Davis WJ: Quantitative analysis of swimmeret beating in the lobster. J Exp Biol 1968;48: 643-662.

158 Davis WJ: The neuromuscular basis of lobster swimmeret beating. J Exp Zool 1968;168: 363-378.

159 Wiersma CAG, Ikeda K: Interneurons commanding swimmeret movements in the crayfish, Procambarus clarkii (Girard). Comp Biochem Physiol 1964;12:509-525.

160 Heitler WJ: Coupled motoneurones are part of the crayfish swimmeret central oscillator. Nature 1978;275:231-233.

161 Sherff CM, Mulloney B: Tests of the motor neuron model of the local pattern-generating circuits in the swimmeret system. J Neurosci 1996;16:2839-2859.

162 Kravitz EA, Kuffler SW, Potter DD, van Gelder NM: Gamma-aminobutyric acid and other blocking compounds in crustacea. 2 . Peripheral nervous system. J Neurophysiol 1963;26:729-738

163 Takeuchi A, Takeuchi N: Localized action of GABA on the crayfish muscle. J Physiol 1965; 177:225-238.

164 Takeuchi A, Takeuchi N: The effect on crayfish muscle of iontophoretically applied glutamate. J Physiol 1964;170:296-317.
165 Dekin MS: Permeability changes induced by $L$-glutamate at the crayfish neuromuscular junction. J Physiol 1983;341:105-125.

166 Mulloney B: During fictive locomotion, graded synaptic currents drive bursts of impulses in swimmeret motor neurons. J Neurosci 2003;23:5953-5962.

167 Paul DH, Mulloney B: Local interneurons in the swimmeret system of the crayfish. J Comp Physiol 1985; 156:489-502.

168 Murchison D, Chrachri A, Mulloney B: A separate local pattern-generating circuit controls the movements of each swimmeret in crayfish. J Neurophysiol 1993;70:26202631

169 Namba H, Mulloney B: Coordination of limb movements: Three types of intersegmental interneurons in the swimmeret system and their responses to changes in excitation. $\mathrm{J}$ Neurophysiol 1999;81:2437-2450.

170 Heitler WJ, Pearson KG: Nonspiking interactions and local interneurons in the central pattern generator of the crayfish Pacifastacus leniusculus swimmeret system. Brain Res 1980;187:206-211.

171 Tschuluun N, Hall WM, Mulloney B: Limb movements during locomotion: Tests of a model of an intersegmental coordinating circuit. J Neurosci 2001;21:7859-7869.

172 Stein PSG: Intersegmental coordination of swimmeret motor neuron activity in crayfish. J Neurophysiol 1971;34:310-318.

173 Paul DH, Mulloney B: Intersegmental coordination of swimmeret rhythms in isolated nerve cords of crayfish. J Comp Physiol 1986; 158:215-224.

174 Braun G, Mulloney B: Coordination in the crayfish swimmeret system: Differential excitation causes changes in intersegmental phase. J Neurophysiol 1995;73:880-885.

175 Mulloney B: A test of the excitability-gradient hypothesis in the swimmeret system of crayfish. J Neurosci 1997; 17:1860-1868.

176 Skinner FK, Mulloney B: Intersegmental coordination of limb movements during locomotion: Mathematical models predict circuits that drive swimmeret beating. J Neurosci 1998;18:3831-3842.

177 Jones SR, Mulloney B, Kaper TJ, Kopell N: Coordination of cellular pattern-generating circuits that control limb movements: The sources of stable differences in intersegmental phases. J Neurosci 2003;23:3457-3468.

178 Davis WJ, Kennedy D: Command interneurons controlling swimmeret movements in the lobster. 1. Types of effects on motoneurons. J Neurophysiol 1972;35:1-12.

179 Davis WJ, Kennedy D: Command interneurons controlling swimmeret movements in the lobster. 2. Interaction of effects on motoneurons. J Neurophysiol 1972;35:13-19.

180 Acevedo LD, Hall WM, Mulloney B: Proctolin and excitation of the crayfish swimmeret system. J Comp Neurol 1994;345:612-627.

181 Mulloney B, Acevedo LD, Bradbury AG: Modulation of the crayfish swimmeret rhythm by octopamine and the neuropeptide proctolin. J Neurophysiol 1987;58:584-597.
182 Barthe J-Y, Bevengut M, Clarac F: In vitro, proctolin and serotonin induced modulations of the abdominal motor system activities in crayfish. Brain Res 1993;623:101-109.

183 Chrachri A, Neil DM: Interaction and synchronization between two abdominal motor systems in crayfish. J Neurophysiol 1993;69: 1373-1383.

184 Barthe JY, Mons N, Cattaert D, Geffard M, Clarac F: Dopamine and motor activity in the lobster Homarus gammarus. Brain Res 1989; 497:368-373.

185 Braun G, Mulloney B: Cholinergic modulation of the swimmeret motor system in crayfish. J Neurophysiol 1993;70:2391-2398.

186 Mulloney B, Namba H, Agricola HJ, Hall WM: Modulation of force during locomotion: Differential action of crustacean cardioactive peptide on power-stroke and return-stroke motor neurons. J Neurosci 1997;17:68726883.

187 Davis WJ: Reflex organization in the swimmeret system of the lobster. 1. Intrasegmental reflexes. J Exp Biol 1969;51:547-563.

188 Davis WJ: Reflex organization in the swimmeret system of the lobster. 2. Reflex dynamics. J Exp Biol 1969;51:565-573.

189 Killian KA, Page CH: Mechanosensory afferents innervating the swimmerets of the lobster. 2. Afferents activated by hair deflection. J Comp Physiol 1992;170:501-508.

190 Killian KA, Page CH: Mechanosensory afferents innervating the swimmerets of the lobster. 1. Afferents activated by cuticular deformation. J Comp Physiol 1992;170:491-500.

191 Macmillan DL, Deller SRT: Sensory systems in the swimmerets of the crayfish Cherax destructor and their effectiveness in entraining the swimmeret rhythm. J Exp Biol 1989;144: 279-301.

192 Heitler WJ: Aspects of sensory integration in the crayfish swimmeret system. J Exp Biol 1986;120:387-401.

193 West L, Jacobs GA, Mulloney B: Intrasegmental proprioceptive influences on the period of the swimmeret rhythm in crayfish. J Exp Biol 1979;82:281-288

194 Marder E, Hooper SL, Eisen JS: Multiple neurotransmitters provide a mechanism for the production of multiple outputs from a single neuronal circuit; in Edelman GM, Gall WE, Cowan MW (ed): Synaptic Function. New York, Wiley, 1987, pp 305-327.

195 Benson JA, Cooke IM: Driver potentials and the organization of rhythmic bursting in crustacean ganglia. Trends Neurosci 1984;7:8591.

196 Mulloney B, Skinner FK, Namba H, Hall WM: Intersegmental coordination of swimmeret movements: Mathematical models and neural circuits. Annu NY Acad Sci 1998;860: 266-280.

197 Skinner FK, Mulloney B: Intersegmental coordination of limb movements during locomotion: Mathematical models predict circuits that drive swimmeret beating. J Neurosci 1998;18:3831-3842. 